\title{
The SOCOL version 3.0 chemistry-climate model: description, evaluation, and implications from an advanced transport algorithm
}

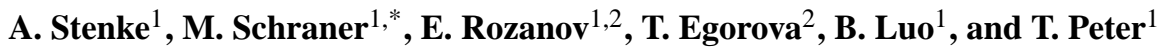 \\ ${ }^{1}$ Institute for Atmospheric and Climate Science, ETH Zurich, Switzerland \\ ${ }^{2}$ Physical-Meteorological Observatory/World Radiation Center, Davos, Switzerland \\ *now at: MeteoSwiss, Zurich, Switzerland
}

Correspondence to: A. Stenke (andrea.stenke@env.ethz.ch)

Received: 26 July 2012 - Published in Geosci. Model Dev. Discuss.: 30 October 2012

Revised: 20 July 2013 - Accepted: 24 July 2013 - Published: 9 September 2013

\begin{abstract}
We present the third generation of the coupled chemistry-climate model (CCM) SOCOL (modeling tools for studies of SOlar Climate Ozone Links). The most notable modifications compared to the previous model version are (1) the dynamical core has been updated with the fifth generation of the middle-atmosphere general circulation model MA-ECHAM (European Centre/HAMburg climate model), and (2) the advection of the chemical species is now calculated by a mass-conserving and shape-preserving flux-form transport scheme instead of the previously used hybrid advection scheme. The whole chemistry code has been rewritten according to the ECHAM5 infrastructure and transferred to Fortran95. In contrast to its predecessors, SOCOLvs3 is now fully parallelized. The performance of the new SOCOL version is evaluated on the basis of transient model simulations (1975-2004) with different horizontal (T31 and T42) resolutions, following the approach of the CCMVal-1 model validation activity. The advanced advection scheme significantly reduces the artificial loss and accumulation of tracer mass in regions with strong gradients that was observed in previous model versions. Compared to its predecessors, SOCOLvs3 generally shows more realistic distributions of chemical trace species, especially of total inorganic chlorine, in terms of the mean state, but also of the annual and interannual variability. Advancements with respect to model dynamics are for example a better representation of the stratospheric mean state in spring, especially in the Southern Hemisphere, and a slowdown of the upward propagation in the tropical lower stratosphere. Despite a large number of improvements model deficiencies still remain. Examples include a too-fast
\end{abstract}

vertical ascent and/or horizontal mixing in the tropical stratosphere, the cold temperature bias in the lowermost polar stratosphere, and the overestimation of polar total ozone loss during Antarctic springtime.

\section{Introduction}

The accurate calculation of the advective transport of chemical species is of fundamental importance for the overall performance of coupled chemistry-climate models (CCMs). Deficiencies in the transport scheme may lead to errors in the spatial distribution and temporal evolution of ozone and other chemical trace gases that react with ozone, e.g., chlorine- and bromine-containing species (Schraner et al., 2008; Stenke et al., 2008, 2009). Furthermore, model biases in tracer distributions may negatively affect model dynamics via radiative feedback. The increasing number of chemical species considered and complex feedback processes makes modern chemistry-climate models more and more vulnerable to limitations of applied numerical schemes.

As shown by Schraner et al. (2008), several deficiencies of the first version (vs1.0) of the CCM SOCOL (modeling tool for studies of SOlar Climate Ozone Links, Egorova et al., 2005) were directly related to deficiencies of the semiLagrangian advection scheme (Ritchie, 1985; Williamson and Rasch, 1989) applied for horizontal tracer transport. For a long time, semi-Lagrangian advection schemes were widely used in general circulation models (GCMs) and CCMs. The main advantage of semi-Lagrangian methods 
is that the Courant-Friedrichs-Lewy (CFL) stability condition (Courant et al., 1928) does not need to be fulfilled, enabling large advection time steps (even near the poles, where the small cell sizes provoke the violation of the CFL criterion). In previous model versions an advection time step of two hours has been applied, making SOCOL computationally very efficient. Furthermore, semi-Lagrangian methods are computationally less expensive than, e.g., flux-form schemes (Rasch and Lawrence, 1998). However, this issue is becoming less critical with improvements in modern computer technology. The disadvantage of the semi-Lagrangian approach is the lack of mass conservation, which requires the application of so-called mass fixers after each advection time step (Williamson and Rasch, 1989) to ensure global mass conservation. The application of mass correction on the global scale, however, may lead to artificial mass transport and undesirable accumulation or loss of mass in particular regions. This problem is most dangerous in areas characterized by sharp tracer gradients, such as the edge of the polar vortex. Erroneous concentrations can then be transported to other model layers, leading to non-physical tracer distributions (Schraner et al., 2008).

In SOCOLvs1.0 the deficiencies of the semi-Lagrangian advection scheme became most apparent in the simulated distribution of total organic and inorganic chlorine $\left(\mathrm{CCl}_{\mathrm{y}}{ }^{1}\right)$. Since surface emissions of chlorofluorocarbons (CFCs) and tropospheric wash-out of $\mathrm{HCl}$ are the only source and sink processes of total chlorine in the model, $\mathrm{CCl}_{\mathrm{y}}$ is expected to behave as a passive tracer with a relatively smooth distribution throughout the stratosphere and mesosphere. However, the stratospheric mixing ratio of total inorganic chlorine $\left(\mathrm{Cl}_{\mathrm{y}}\right)$ simulated with SOCOLvs1.0 was up to $30 \%$ higher than the maximum amount of total chlorine $\left(\mathrm{CCl}_{\mathrm{y}}\right)$ entering the stratosphere (see Schraner et al., 2008, their Fig. 1). Moreover, unrealistic $\mathrm{CCl}_{\mathrm{y}}$ minima appeared in high latitudes around $50 \mathrm{hPa}$ during winter and spring, most prominent over Antarctica, with values up to $50 \%$ lower than anywhere else. This example demonstrates the artificial mass accumulation and loss caused by the semi-Lagrangian advection scheme and its mass fixer routine.

Schraner et al. (2008) described a simple, efficient method to reduce these transport-related shortcomings for modeled chlorine, bromine and nitrogen species. The idea of the socalled "family-based mass correction" is based on the fact that relatively smooth tracer distributions, such as those of the $\mathrm{Cl}_{\mathrm{y}}, \mathrm{Br}_{\mathrm{y}}$ and $\mathrm{NO}_{\mathrm{y}}$ families, are much less critical for transport errors than inhomogeneous distributions of individual family members. Therefore, the respective families are transported in addition to the individual family members, and the mass fixer is no longer applied to the family members, but to the transported family. The mixing ratio of the

\footnotetext{
${ }^{1}$ Definition of the total chlorine family within SOCOL: $\left[\mathrm{CCl}_{\mathrm{y}}\right]=[\mathrm{Cl}]+[\mathrm{ClO}]+[\mathrm{HOCl}]+2\left[\mathrm{Cl}_{2}\right]+2\left[\mathrm{Cl}_{2} \mathrm{O}_{2}\right]+[\mathrm{BrCl}]+[\mathrm{HCl}]$ $+\left[\mathrm{ClONO}_{2}\right]+[\mathrm{Cl}$-atoms in ODS $]$
}

transported, mass-corrected family is then used to re-scale the mixing ratios of the family members in every grid box. This method ensures local mass conservation and led to a number of model improvements in SOCOLvs2.

As shown by Schraner et al. (2008), this simple concept, while considerably reducing the deficiencies of the semiLagrangian scheme, cannot fully eliminate them. Firstly, even the $\mathrm{Cl}_{\mathrm{y}}, \mathrm{Br}_{\mathrm{y}}$ and $\mathrm{NO}_{\mathrm{y}}$ families are not completely homogeneous, but have strong gradients at the tropopause. Therefore the mass fixer affects the tracer families themselves. Secondly, the method can only be applied to chemical species belonging to a family. For chemical species without a corresponding family, for example ozone itself, an alternative method has to be applied as, for example, restricting the mass fixer to certain geographical regions (Schraner et al., 2008). However, compared to $\mathrm{Cl}_{\mathrm{y}}$ or $\mathrm{Br}_{\mathrm{y}}$ the stratospheric lifetime of the $\mathrm{O}_{\mathrm{x}}$ family is much shorter, and, therefore, mass conservation during advection becomes less critical than for tracers with a lifetime longer than one year. From all of this it is obvious that a more satisfying approach to the advection problem requires the semi-Lagrangian scheme to be replaced by a more advanced, mass-conserving approach.

Here we present an updated version (vs3) of the SOCOL CCM. The two most important modifications of SOCOLvs3 compared to its predecessors are (1) the underlying general circulation model has been updated from the middle-atmosphere GCM MA-ECHAM4 (European Centre/HAMburg climate model; Roeckner et al., 1996; Manzini and Bengtsson, 1996) to MA-ECHAM5 (Roeckner et al., 2003, 2006; Manzini et al., 2006), and (2) the advection of the chemical trace species is now calculated by the fluxform semi-Lagrangian scheme of Lin and Rood (1996) instead of the previously applied hybrid advection scheme. The hybrid approach has been described in detail by Zubov et al. (1999). The hybrid advection scheme uses the operator splitting approach; i.e., vertical and horizontal transport are calculated separately. In the vertical direction it utilizes the Eulerian scheme proposed by Prather (1986), while in the horizontal direction a semi-Lagrangian scheme (Ritchie, 1985; Williamson and Rasch, 1989) is applied. The advection scheme of Lin and Rood (1996), which is operationally implemented in (MA-)ECHAM5, is a multidimensional fluxform scheme and by construction mass conservative to machine precision. It also can cope with long time steps to make it applicable within GCMs. In addition to mass conservation, the advection scheme of Lin and Rood (1996) satisfies other fundamental requirements for tracer algorithms, such as monotonicity and conservation of tracer correlations. Furthermore, the advection scheme very effectively prevents numerical diffusion.

In SOCOLvs1 and vs2, the chemistry module code was not parallelized and the model could therefore only be run on a single CPU. To take advantage of modern, parallel computer architectures the parallelization of the chemistry code was a further, important goal. For SOCOLvs3 the chemistry code 
has been transferred to Fortran 95 and completely redesigned according to the ECHAM5 infrastructure and modularity.

The intention of this paper is to provide a technical description of the new version SOCOLvs3 and to evaluate the performance of the upgraded model with respect to model dynamics and chemistry, documenting model improvements and identifying remaining deficiencies. As in previous model evaluation publications, this study is based on transient model simulations with horizontal resolution T31 $\left(3.75^{\circ} \times 3.75^{\circ}\right)$ covering the years $1975-2004$, including numerous natural and anthropogenic forcings. In addition, we here also use horizontal resolution T42 $\left(2.8^{\circ} \times 2.8^{\circ}\right)$. The analysis of the model results follows the guidelines of the WCRP/SPARC (World Climate Research Programme/Stratospheric Processes and their Role in Climate) chemistry-climate model validation activity CCMVal1 (Eyring et al., 2006). The CCMVal-2 initiative (SPARC, 2010) used a more advanced and extensive set of diagnostics, which goes beyond the scope of this paper.

The following section provides a description of the new model version SOCOLvs3. The experimental set-up of the model simulations is briefly described in Sect. 3. Section 4 shows the effects of the replaced advection scheme using the example of the chlorine family. In Sect. 5, the new model version is evaluated against observations, focusing on stratospheric dynamics and chemistry. Differences from the previous model version SOCOLvs2 are also documented.

\section{SOCOLvs3 model description}

The coupled chemistry-climate model SOCOL consists of the middle-atmosphere GCM MA-ECHAM and a modified version of the chemistry-transport model (CTM) MEZON (Model for Evaluation of oZONe trends; Rozanov et al., 1999, 2001; Egorova et al., 2001, 2003; Hoyle, 2005; Schraner et al., 2008). The GCM and CTM are interactively coupled by the 3-dimensional fields of temperature and wind, and by the radiative forcing induced by water vapor, ozone, methane, nitrous oxide, and chlorofluorocarbons (CFCs). The CTM is called every $2 \mathrm{~h}$, making SOCOL computationally very efficient. From a technical point of view, the coupling between GCM and CTM has been greatly simplified. The MEZON code has been transferred from Fortran77 to Fortran95 and completely rewritten according to the ECHAM5 infrastructure. In contrast to previous versions, the model can now be run in parallel mode. On parallel computing infrastructure, this enables a further reduction of the wall clock time, which has already been an attractive feature of SOCOLvs1 and vs2. For comparison, one model year with SOCOLvs2 required about two days on a single CPU (Schraner et al., 2008), while SOCOLvs3 requires about $4 \mathrm{~h}$ for one model year (on 32 CPUs, T31 horizontal resolution, 39 vertical levels).

\subsection{MA-ECHAM5}

MA-ECHAM5 (Manzini et al., 2006) is the recent middleatmosphere version of the ECHAM GCM developed at the MPI for Meteorology, Hamburg. ECHAM originally evolved from the spectral weather prediction model of the European Centre of Medium-Range Weather Forecasts (ECMWF; Simmons et al., 1989), extended by a comprehensive parameterization package for climate applications. A detailed model description of ECHAM5 is given by Roeckner et al. (2003, 2006). Within SOCOLvs3, the MA-ECHAM model version 5.4.00 is used.

All versions of ECHAM are spectral general circulation models based on the primitive equations with the prognostic variables temperature, vorticity, divergence, logarithm of surface pressure, humidity and cloud water. Tracer transport and model physics are calculated on a Gaussian transform grid. In the vertical, a hybrid sigma $p$ coordinate system is used. The middle-atmosphere version MA-ECHAM5 can be run with 39 or 90 vertical levels. The model top is centered at $0.01 \mathrm{hPa}(\sim 80 \mathrm{~km})$, for both vertical resolutions. Within SOCOLvs3, 39 levels are used by default. The model time step for dynamical processes and physical parameterizations is $15 \mathrm{~min}$.

Compared to ECHAM4, several parameterizations of physical processes have been changed in ECHAM5. A new parameterization of stratiform clouds has been developed, including a separate treatment of cloud water and cloud ice, advanced cloud microphysics and a statistical model for the calculation of cloud cover. The description of coupling processes between the land surface and the atmosphere has been improved, including a new land surface dataset.

Water vapor, cloud variables and chemical species are advected by a flux-based mass-conserving and shapepreserving transport scheme (Lin and Rood, 1996), instead of the semi-Lagrangian approach used in ECHAM4. The scheme is designed for time steps of arbitrary length. Thus, as for a semi-Lagrangian scheme, the CFL stability criterion does not need to be fulfilled.

The shortwave radiation scheme is based on the radiation code of the ECMWF (Fouquart and Bonnel, 1980), and basically the same as in ECHAM4. However, the spectral resolution has been increased from 2 to 6 bands, with three bands in the UV-visible range $(185-250 \mathrm{~nm}, 250-440 \mathrm{~nm}$, $440-690 \mathrm{~nm})$ and three bands in the near-IR range $(690$ $1190 \mathrm{~nm}, 1190-2380 \mathrm{~nm}, 2380-4000 \mathrm{~nm}$ ) (Cagnazzo et al., 2007). To obtain realistic heating rates in the mesosphere, SOCOL additionally takes account of the absorption by $\mathrm{O}_{2}$ and $\mathrm{O}_{3}$ in the Lyman-alpha emission line of solar hydrogen $(121.6 \mathrm{~nm})$ and the $\mathrm{O}_{2}$ Schumann-Runge absorption bands $(175-200 \mathrm{~nm})$; see Egorova et al. (2004). This parameterization is not part of the original (MA-)ECHAM5 code.

The longwave radiation scheme has also been changed from that of ECHAM4: instead of the emissivity method applied in ECHAM4, the RRTM (Rapid Radiative Transfer 
Model) scheme (Mlawer et al., 1997), based on the more accurate $k$ correlated method, is used. Compared to MAECHAM4, the number of spectral intervals has been increased from 6 to 16 longwave bands. Full radiative transfer calculations are performed every $2 \mathrm{~h}$. The calculated longwave fluxes are kept constant over the whole radiation time step, while the shortwave fluxes are updated each dynamical time step, accounting for changes in the local zenith angle.

The parameterization of the effects of the gravity wave spectrum is based on the so-called Doppler spread theory and follows the formulation of Hines (1997a, b). The source spectrum of the Hines scheme is given by Manzini et al. (2006).

\subsection{MEZON}

The CTM MEZON has the same vertical and horizontal grid as MA-ECHAM5; i.e., the chemical calculations are performed on the Gaussian grid with a hybrid sigma $p$ coordinate in the vertical. The model includes 41 chemical species of the oxygen, hydrogen, nitrogen, carbon, chlorine and bromine groups, which are determined by 140 gasphase reactions, 46 photolysis reactions and 16 heterogeneous reactions in/on aqueous sulfuric acid aerosols as well as three types of polar stratospheric clouds (PSCs), supercooled ternary solution (STS) droplets, water ice and nitric acid trihydrate (NAT).

The parameterization of heterogeneous chemistry is based on Carslaw et al. (1995). It takes into account $\mathrm{HNO}_{3}$ uptake by aqueous sulfuric acid aerosols resulting in the formation of STS. The parameterization of the liquid-phase reactive uptake coefficients follows Hanson and Ravishankara (1994) and Hanson et al. (1996). The PSC scheme for water ice uses a prescribed particle number density of $0.01 \mathrm{~cm}^{-3}$ (instead of $0.1 \mathrm{~cm}^{-3}$ used in SOCOLvs2) and assumes that the cloud particles are in thermodynamic equilibrium with their gaseous environment. NAT is formed if the partial pressure of $\mathrm{HNO}_{3}$ exceeds its saturation pressure, assuming a mean particle radius of $5 \mu \mathrm{m}$ for NAT. The particle number densities are limited by an upper boundary of $5 \times 10^{-4} \mathrm{~cm}^{-3}$ to account for the fact that observed NAT clouds are often strongly supersaturated, which is a numerically cheap thermodynamic approximation for the slow growth kinetics of these particles. The sedimentation of NAT and water ice is based on the Stokes theory as described in Pruppacher and Klett (1997). Water ice and NAT are not explicitly transported, but are evaporated back to water vapor and gaseous $\mathrm{HNO}_{3}$ after each chemical time step, transported in the vapor phase, and then depending on the saturation conditions regenerated in the next time step with the thermodynamic approximation described above.

The chemical reaction rate coefficients are taken from Sander et al. (2006). Photolysis rates are calculated at every chemical time step using a look-up-table approach (Rozanov et al., 1999), including effects of the solar irradiance variability. The impact of cloudiness on photolysis rates already has been included in an extended tropospheric version of SOCOL, but not in the operational model, as presented here. The chemical solver is based on the implicit iterative NewtonRaphson scheme (Ozolin, 1992; Stott and Harwood, 1993). Chemical calculations are performed every $2 \mathrm{~h}$.

MEZON considers dry deposition of $\mathrm{O}_{3}, \mathrm{CO}, \mathrm{NO}, \mathrm{NO}_{2}$, $\mathrm{HNO}_{3}$ and $\mathrm{H}_{2} \mathrm{O}_{2}$. Dry deposition velocities over land and sea are based on Hauglustaine et al. (1994). Furthermore, the tropospheric wash-out of $\mathrm{HNO}_{3}$ is described by a constant removal rate of $4 \times 10^{-6} \mathrm{~s}^{-1}$; i.e., every two hours $2.8 \%$ of the tropospheric $\mathrm{HNO}_{3}$ is removed.

In contrast to SOCOLvs2, the transport of the chemical trace species is calculated with the advection scheme of Lin and Rood (1996) implemented in MA-ECHAM5, instead of the hybrid scheme of Zubov et al. (1999), which was part of MEZON. As in the previous model version, each individual chemical species of the $\mathrm{Cl}_{\mathrm{y}}, \mathrm{Br}_{\mathrm{y}}$, and $\mathrm{NO}_{\mathrm{y}}$ families are transported (as well as the families themselves in order to still be able to apply a family correction; see below). In contrast to previous model versions, the transport is calculated every dynamical time step (15 min) instead of every $2 \mathrm{~h}$.

SOCOLvs2 differentiated two water vapor fields: the one of the GCM used below $100 \mathrm{hPa}$, which included the complete hydrological cycle in the troposphere, and the one of the CTM used above $100 \mathrm{hPa}$ to account for water vapor production/destruction by chemical reactions. In vs3, this unsatisfying separation has become obsolete. SOCOLvs3 considers only one water vapor field, i.e., the ECHAM5 water vapor. Large-scale advection, cumulus convection and the tropospheric hydrological cycle are calculated by the GCM, while chemical water vapor production/destruction as well as PSC formation are calculated by the chemistry module. To avoid interference of the ECHAM5 cloud scheme and the PSC routine, we ensure that the ECHAM5 parameterization of stratiform clouds is deactivated in the stratosphere.

\section{Model set-up and boundary conditions}

The evaluation of the new model version SOCOLvs 3 is based on two transient model simulations from 1975 to 2004, for T31 and T42 horizontal resolutions. Both model simulations were performed with a vertical resolution of 39 levels. The simulation set-up follows the specifications of the CCMVal2 reference simulation REF-B1 (Eyring et al., 2008), which was designed to reproduce past atmospheric conditions as realistically as possible. The simulations are driven by several natural and anthropogenic forcings, such as the $11 \mathrm{yr}$ solar cycle, the quasi-biennial oscillation (QBO), stratospheric sulfate aerosol loading, as well as changes in trace gas concentrations.

Global sea surface temperatures (SSTs) and sea ice coverage (SIC) are prescribed as monthly means following the HadISST1 dataset provided by the UK Met Office Hadley Centre (Rayner et al., 2003). The dataset is based on merged satellite and in situ observations. 
Atmospheric concentrations of the most relevant greenhouse gases $\left(\mathrm{CO}_{2}, \mathrm{CH}_{4}, \mathrm{~N}_{2} \mathrm{O}\right)$ for the years before 1996 are prescribed following IPCC (2001). This time series is merged with NOAA observations from 1997 to 2004 (Eyring et al., 2008). Time-dependent surface mixing ratios of ozonedepleting substances (ODS) are taken from WMO (2007). Emission fluxes of $\mathrm{CO}$ and nitrogen oxides $\left(\mathrm{NO}_{\mathrm{x}}\right)$ from industrial sources, traffic and biomass burning are taken from the RETRO dataset (Schultz and Rast, 2007), whereas emissions from soils and oceans follow Horowitz et al. (2003). For $\mathrm{NO}_{\mathrm{x}}$ emissions from aircraft the dataset described by Dameris et al. (2005) is used. $\mathrm{NO}_{\mathrm{x}}$ emissions from lightning are based on the satellite-based dataset of Turman and Edgar (1982), with a global annual $\mathrm{NO}_{\mathrm{x}}$ production of $4 \mathrm{Tg}(\mathrm{N}) \mathrm{yr}^{-1}$.

The chemical effect of the enhanced stratospheric aerosol loading after the two major volcanic eruptions of $\mathrm{El}$ Chichón (1982) and Mount Pinatubo (1991) is considered by prescribing observed sulfate aerosol surface area densities (SADs) as monthly means. The SAD time series is based on SAGE I, SAGE II, SAM II and SME observations and covers the period from 1979 to 2005 . More details about the merged SAD time series are given in Eyring et al. (2008). The radiative effects of volcanic eruptions are calculated online. For this purpose the extinction coefficient, asymmetry factor, and single scattering albedo of the stratospheric aerosol record were pre-calculated using Mie theory as described in Schraner et al. (2008), with the aerosol surface area density and the effective aerosol radius (both obtained from the SAGE dataset by Thomason and Peter, 2006) as input parameters. A tropospheric aerosol climatology (Lohmann et al., 1999) is used for the calculation of local heating rates and shortwave backscatter. Aerosol-cloud interactions and heterogeneous chemistry on tropospheric aerosols or clouds are not considered in SOCOL.

The QBO is forced by a linear relaxation ("nudging") of the simulated zonal winds in the equatorial stratosphere to a time series of observed wind profiles (Giorgetta, 1996). The nudging is applied between $20^{\circ} \mathrm{N}$ and $20^{\circ} \mathrm{S}$ from $90 \mathrm{hPa}$ up to $3 \mathrm{hPa}$. Within the QBO core domain $\left(10^{\circ} \mathrm{N}-10^{\circ} \mathrm{S}, 50\right.$ $8 \mathrm{hPa}$ ) the relaxation time is uniformly set to 7 days; outside this region the damping depends on latitude and altitude. It should be mentioned that the described nudging approach is only necessary for the model version with 39 levels. The version of MA-ECHAM5 with 90 vertical levels spontaneously simulates a QBO (Giorgetta et al., 2006).

The variability of solar irradiance has been taken into account for the calculations of the solar radiation fluxes, photolysis and heating rates, using the time series of monthly mean extra-terrestrial spectral solar irradiance (SSI) compiled by Lean et al. (2005). These data were used to calculate the integrated extra-terrestrial solar fluxes for the six intervals of the MA-ECHAM5 solar radiation code, as well as the parameters for the parameterization of the heating rates due to absorption at wavelengths of the Lyman-alpha line and
Schumann-Runge bands. The SSI time series was also used to calculate monthly look-up tables for the calculation of the photolysis rates in the chemical part of the model.

\section{Effects of the new advection scheme}

In this section, we demonstrate the effects of the new advection scheme using the example of the total chlorine family (total inorganic plus organic chlorine, $\mathrm{CCl}_{\mathrm{y}}$ ). Except exchange with the troposphere, there are no further sources or sinks of total chlorine in the stratosphere. Therefore, $\mathrm{CCl}_{\mathrm{y}}$ is expected to show a smooth distribution throughout the stratosphere and mesosphere. If the model produced an unrealistic distribution of $\mathrm{CCl}_{\mathrm{y}}$, this should be directly related to deficiencies of the advection scheme or of the chemical solver. A violation of mass conservation by the chemical solver can be excluded in SOCOL, since the number of the $\mathrm{Cl}_{\mathrm{y}}, \mathrm{Br}_{\mathrm{y}}$ and $\mathrm{NO}_{\mathrm{y}}{ }^{2}$ molecules is strictly conserved during a chemical step (at least within numerical precision). As shown by Schraner et al. (2008), previous versions of SOCOL suffered from problems in simulating a realistic $\mathrm{CCl}_{\mathrm{y}}$ distribution in the region of the polar vortex. Several $\mathrm{CCl}_{\mathrm{y}}$ family members show strong gradients at the edge of the polar vortex, representing a challenge for advection schemes.

Figure 1a and b show the 1985-1990 August zonalmean $\mathrm{CCl}_{\mathrm{y}}$ values for simulations using the hybrid advection scheme without (SOCOLvs1.3) and with (SOCOLvs2) family-based mass correction. Figure $1 \mathrm{c}$ and d show corresponding simulations for SOCOLvs3 using the advection scheme of Lin and Rood (1996). Since CFC surface mixing ratios were increasing during this period, highest $\mathrm{CCl}_{\mathrm{y}}$ concentrations are expected in the troposphere and lowest values at the high latitudes of the stratosphere and in the mesosphere, where the air is oldest. The model deficiencies of the previous SOCOL versions mentioned in Sect. 1 are clearly visible in Fig. 1a and b: vs1.3 especially shows a very inhomogeneous stratospheric $\mathrm{CCl}_{\mathrm{y}}$ distribution with a pronounced minimum in the region of the southern polar vortex. In vs2, the artificial mass loss in the southern polar vortex is considerably reduced, but still present. Moreover, $\mathrm{CCl}_{\mathrm{y}}$ concentrations in the strato- and mesosphere are nearly as high as or even higher than in the troposphere. As shown in the analysis of Schraner et al. (2008), this problem is most likely caused by artificial mass transport of $\mathrm{CCl}_{\mathrm{y}}$ from high latitudes towards the Equator in late winter/early spring and a subsequent upward transport into the middle and upper stratosphere via the tropical pipe, due to mixing ratio gradients at the edges of the vortex and pipe.

Applying the scheme of Lin and Rood (1996) leads to a substantial improvement in the simulated $\mathrm{CCl}_{\mathrm{y}}$ distribution (Fig. 1c and d). However, without family-based mass fixing (Fig. 1c) we remain having an unrealistic $\mathrm{CCl}_{\mathrm{y}}$ minimum in

\footnotetext{
${ }^{2} \mathrm{NO}_{\mathrm{y}}$ sink reactions as well as stratospheric $\mathrm{NO}_{\mathrm{y}}$ production are taken into account in mass conservation.
} 
(a) $\mathrm{CCl}_{\mathrm{y}}$ August vs1.3

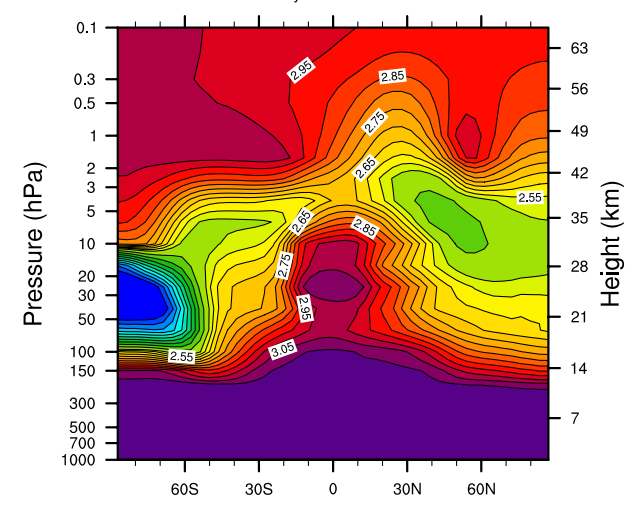

(c) $\mathrm{CCl}_{\mathrm{y}}$ August vs3.0 nofamcor

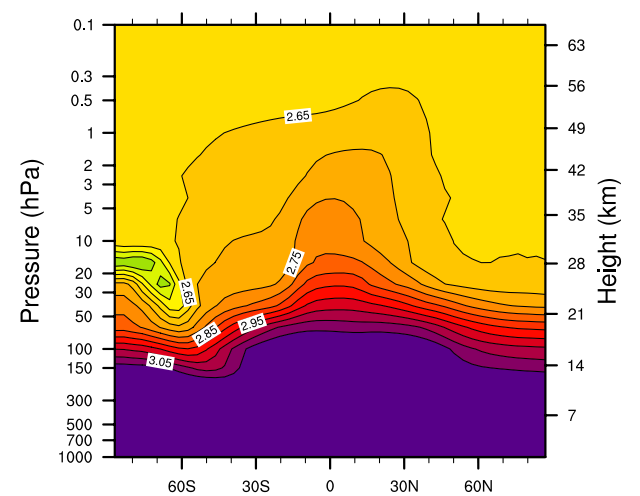

(b) $\mathrm{CCl}_{y}$ August vs2.0

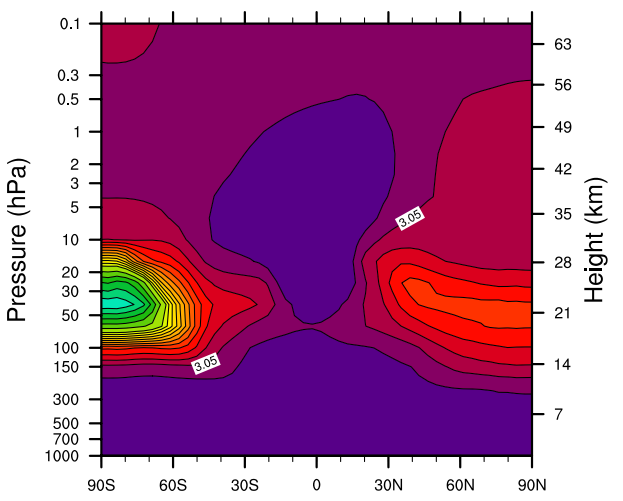

(d) $\mathrm{CCl}_{\mathrm{y}}$ August vs 3.0

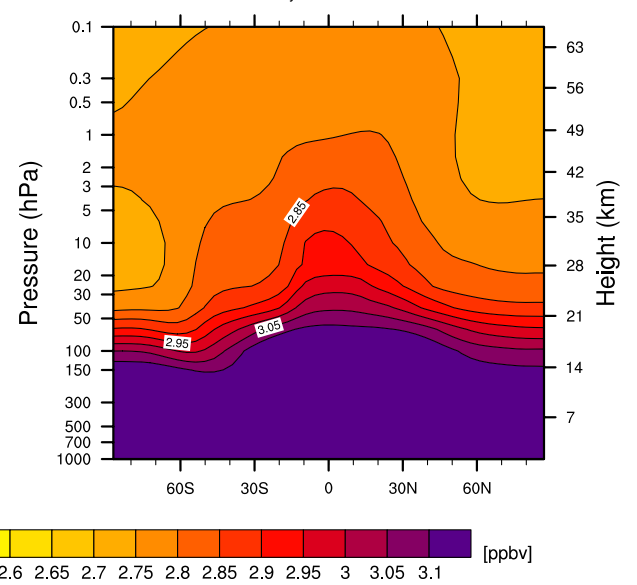

Fig. 1. Modeled zonal-mean mixing ratio of total organic plus inorganic chlorine $\left(\mathrm{CCl}_{\mathrm{y}}\right)$ in August for SOCOL with resolution T31 (a) vs1.3, (b) vs2, (c) vs3 without family correction, and (d) vs3 final version. Means calculated for the period 1985-1990.

the region of the polar vortex, but to a minor degree. Furthermore, mesospheric $\mathrm{CCl}_{\mathrm{y}}$ mixing ratios are about $5 \%$ smaller than expected: tropospheric CFC concentrations were increasing by $0.1 \mathrm{ppbv} \mathrm{yr}^{-1}$ during the late 1980s; assuming a modeled age of air of $4 \mathrm{yr}$ in the mesosphere and in the high-latitude stratosphere (Manzini and Feichter, 1999), mesospheric $\mathrm{CCl}_{\mathrm{y}}$ mixing ratios are estimated to be around $0.4 \mathrm{ppbv}$ lower than tropospheric values, which is not the case in Fig. 1c. Applying the family-based mass correction also for the advection scheme of Lin and Rood (1996) helps overcome the problem of the artificial minimum in the region of the polar vortex. In Fig. 1d the difference between tropospheric and mesospheric $\mathrm{CCl}_{\mathrm{y}}$ mixing ratios is as high as expected.

Our results are corroborated by a previous study of Rasch et al. (2006), who investigated the characteristics of atmospheric tracer transport using a spectral, a semi-Lagrangian, and a finite volume scheme, in which all equations are expressed in flux form. In this intercomparison, the finite volume scheme showed the best performance: It is conservative, less diffusive than the other schemes, and shows the highest consistency between model dynamics and tracer transport.

It is important to note that although the advection scheme of Lin and Rood (1996) itself is perfectly mass-conserving, violation of mass conservation occurs in any model with a hybrid sigma $p$ coordinate system like ECHAM5, where the pressure levels (and the thickness of the model layers) depend on the current surface pressure. This problem is caused by an inconsistency between the air mass change calculated by the advection scheme and the air mass change determined by the change in surface pressure (Jöckel et al., 2001). In other words, the wind field, which is determined by solving the basic equations in the spectral core of ECHAM5, is generally not consistent with the change of the underlying pressure grid. In ECHAM5, this so-called wind-mass inconsistency is ignored, which may lead to a violation of global tracer mass conservation. It should be noted that the problem of wind-mass inconsistency described above only applies to pressure levels influenced by the underlying surface pressure. For a pressure grid defined by time-independent isobars, a flux-form scheme is perfectly mass-conserving. For 
the sigma $p$-coordinate used in MA-ECHAM5, this is the case for all model layers above $75 \mathrm{hPa}$.

The violation of mass conservation for a flux-form advection scheme implemented in a GCM was analyzed in detail by Jöckel et al. (2001). They found that the problem is most critical for regions of steep gradients, e.g., at the tropopause or at the edge of the polar vortex. In the case of a homogeneously initialized tropospheric tracer, mass loss occurred when the tracer was transported across the tropopause. A similar phenomenon is also visible in the case of $\mathrm{CCl}_{\mathrm{y}}$ without family-based mass correction (Fig. 1c): the upward transport of tropospheric $\mathrm{CCl}_{\mathrm{y}}$ into the stratosphere is clearly underestimated, suggesting an artificial loss of $\mathrm{CCl}_{\mathrm{y}}$ on its way through the tropopause.

Increasing the horizontal model resolution can reduce the violation of global mass conservation, but not completely avoid it. Other approaches to deal with the mass mismatch suffer from various disadvantages: for example, simple mass fixers either lead to non-physical tracer transport or artificially increase spatial gradients, and the mass-conserving grid-to-grid transformation presented by Jöckel et al. (2001) causes an additional, non-negligible vertical diffusion.

Jöckel et al. (2001) pointed out that despite the problems concerning mass conservation on a hybrid grid, flux-form advection schemes should not be rejected, because the problem of wind-mass inconsistency in principle applies also to any other advection scheme as well. In the case of a semiLagrangian scheme, the advection scheme itself produces an additional error in mass conservation, which in most cases exceeds that of the wind-mass inconsistency. Figure 1 confirms that switching from a semi-Lagrangian scheme to the advection scheme of Lin and Rood (1996) leads to an enormous improvement, even without family-based mass correction. The best way to avoid the problem of wind-mass inconsistency would be a grid-point dynamical core instead of the presently used spectral core. This approach has been already implemented in several CCMs (e.g., WACCM, GEOSCCM). The joint ICON project of the MPI for Meteorology in Hamburg and the Deutscher Wetterdienst (DWD) aims at developing a dynamical core that solves the equations of motion in grid-point space (http://www.mpimet.mpg.de/en/science/ models/icon.html).

\section{Evaluation of SOCOLvs3}

Subsequently we evaluate the new model version SOCOLvs3 by comparing with observations and with SOCOLvs2, focusing on stratospheric dynamics and chemistry. SOCOLvs2 was extensively evaluated within CCMVal-2 (SPARC, 2010). A detailed description of SOCOLvs 2 is given in Schraner et al. (2008). The SOCOLvs2 simulations are identical to the CCMVal-2 REF-B1 scenario; i.e., they cover the time period 1960-2005. The boundary conditions are mostly identical to the SOCOLvs3 simulations. For SOCOLvs2 three ensemble members (T31) are available, whereas for SOCOLvs3 we use one realization for each horizontal resolution, T31 and T42. An overview of the applied diagnostics and the respective reference datasets is given in Table 1.

\subsection{Stratospheric dynamics}

Following previous CCMVal assessments (Eyring et al., 2006; SPARC, 2010), we compare simulated stratospheric temperatures with the ERA-40 (Uppala et al., 2005) and ERA-Interim (Simmons et al., 2006) reanalyses as well as the NCEP (Gelman et al., 1996) and UKMO (Swinbank and O'Neill, 1994) stratospheric analyses. The mean winter and spring temperature biases in polar regions are shown in Fig. 2. In the lowermost stratosphere (LMS) both SOCOL versions show a cold bias of comparable magnitude. Running SOCOLvs3 in T42 horizontal resolution reduces the cold bias in the LMS of both hemispheres by $1-2 \mathrm{~K}$. The largest temperature bias $(-10 \mathrm{~K})$ is found in the northern LMS in spring, whereas in the Southern Hemisphere (SH) spring both model versions perform similarly, with a bias of about $-4 \mathrm{~K}$. It should be noted that the described cold bias is a widespread feature of CCMs (Eyring et al., 2006; SPARC, 2010). The reasons for the cold bias are not yet fully understood and might differ between different models (e.g., Pawson et al., 2000). For example, Stenke et al. (2008) found that the cold bias in the CCM E39C was partly caused by a severe wet bias in the extratropical LMS, resulting in an excessive longwave cooling.

Between 100 and $10 \mathrm{hPa}$ the comparison can be summarized as follows: in the $\mathrm{NH}$ all model versions expect SOCOLvs2 during springtime lie within the \pm 1 standard deviation range of ERA-40, with SOCOLvs3 simulating slightly higher temperatures than SOCOLvs2. During SH winter all versions show a good agreement with ERA-40. In SH spring SOCOLvs3 again lies within the ERA-40 interannual variability, whereas SOCOLvs2 is significantly colder (the "cold pole" problem). It is clear that this improvement by several degrees Kelvin is related to and has repercussions for the simulation of the Antarctic ozone hole.

In the upper stratosphere radiosondes are generally not available and, consequently, the uncertainties become quite large (Randel et al., 2004). Within this atmospheric region there are remarkable differences between the different reanalysis, and all model versions show large positive temperature deviations relative to ERA-40, with up to $14 \mathrm{~K}$ in the winter SH. Generally, SOCOLvs2 shows a better agreement with ERA-40, whereas SOCOLvs3 agrees very well with the UKMO reanalysis. The evaluation of upper-stratospheric temperatures has to be done with care since the ERA-40 reanalysis shows a general cold temperature bias of around $5 \mathrm{~K}$ within this region $(2-5 \mathrm{hPa}$ ) (Randel et al., 2004). As mentioned above, one of the main modifications to MAECHAM5 is the increased spectral resolution of the solar radiation scheme, allowing a more realistic representation of 
Table 1. Diagnostics and observational data used in this study.

\begin{tabular}{|c|c|c|}
\hline Process & Diagnostics & Observations \\
\hline \multirow[t]{3}{*}{ Dynamics } & High-latitude temperature biases (Fig. 2) & $\begin{array}{l}\text { ERA-40 (Uppala et al., 2005), } \\
\text { ERA-Interim (Simmons et al., 2006), } \\
\text { NCEP, UKMO Reanalyses (Eyring et al., 2006) }\end{array}$ \\
\hline & Easterlies at $60^{\circ} \mathrm{S}$ (Fig. 3) & ERA-40, ERA-Interim \\
\hline & Heat flux $100 \mathrm{hPa}$ (Fig. 4) & ERA-40, NCEP \\
\hline \multirow[t]{2}{*}{ Transport } & Vertical and latitudinal profiles of $\mathrm{CH}_{4}$ (Fig. 6) & HALOE (Grooß and Russell, 2005) \\
\hline & Tape recorder (Fig. 8) & HALOE \\
\hline UTLS & Seasonal cycle of $T$ and $\mathrm{H}_{2} \mathrm{O}, 100 \mathrm{hPa}$, Eq (Fig. 5) & ERA-40, ERA-Interim, HALOE \\
\hline \multirow[t]{2}{*}{ Chemistry } & $\begin{array}{l}\text { Vertical and latitudinal profiles of } \mathrm{H}_{2} \mathrm{O} \text { (Fig. 7), } \\
\mathrm{Cl} \text { species (Fig. 9), } \mathrm{O}_{3} \text { (Fig. 10) }\end{array}$ & HALOE \\
\hline & Total ozone column (Fig. 11) & NIWA (Bodeker et al., 2005) \\
\hline
\end{tabular}
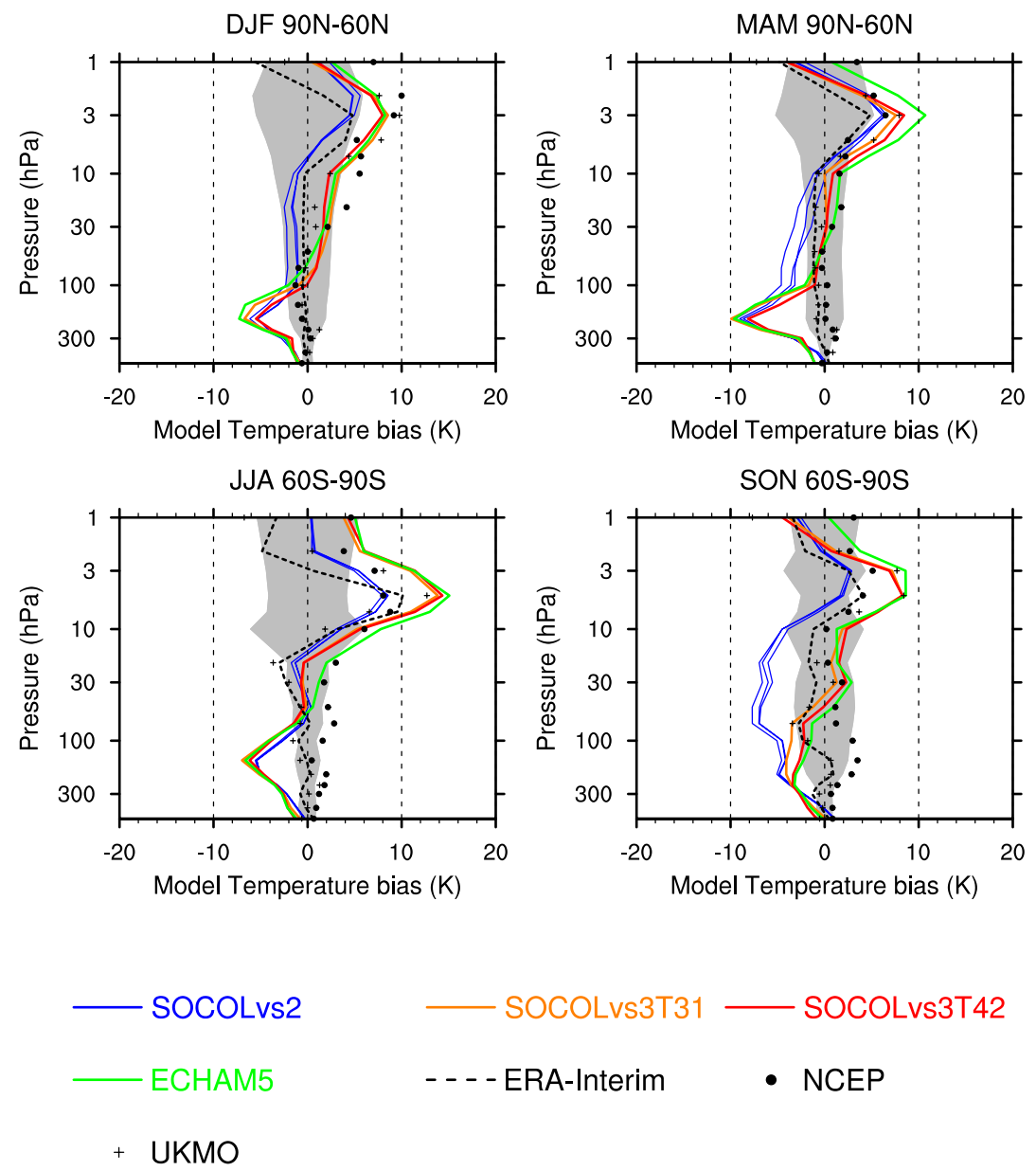

Fig. 2. Climatological mean (1980-1999) temperature biases relative to the ERA-40 reanalysis for 60-90 $\mathrm{N}$ (top) and 60-90 $\mathrm{S}$ (bottom) during winter (left) and spring (right). Biases are calculated for SOCOLvs2 (blue lines, 3 ensemble members), SOCOLvs3 T31 horizontal resolution (orange line), SOCOLvs3 T42 horizontal resolution (red line), MA-ECHAM5 T31 horizontal resolution (green line) and for ERA-Interim (dashed black line, 1989-1999), NCEP (dots, 1980-1999) and UKMO (crosses, 1992-2001) reanalyses. The grey area shows ERA-40 plus and minus 1 standard deviation about the climatological mean. 
ozone absorption in the stratosphere (Cagnazzo et al., 2007). The modifications applied to the radiation scheme lead to a significant warming of almost the entire middle atmosphere, with the strongest temperature increase of about $6 \mathrm{~K}$ at the summer stratopause. The higher stratospheric temperatures are in better agreement with the NCEP analysis that was used by Cagnazzo et al. (2007) for model evaluation. These changes in the shortwave radiation scheme might explain a part of the warming of the upper stratosphere in SOCOLvs3. However, it should be mentioned that the pure GCM MAECHAM5, without coupled chemistry (green line in Fig. 2), shows similar temperature biases in the polar winter stratosphere to SOCOLvs3. During other seasons (spring and summer, not shown) MA-ECHAM5 shows up to $5 \mathrm{~K}$ higher temperatures in the upper stratosphere. These differences are most probably related to different stratospheric water vapor concentrations: since MA-ECHAM5 does not include chemical water vapor production, upper-stratospheric water vapor concentrations in MA-ECHAM5 are 2-3 ppmv lower than in SOCOLvs3, resulting in less longwave cooling in MAECHAM5. Comparing stratospheric ozone distributions in MA-ECHAM5 and SOCOLvs3 reveals largest differences in polar fall and winter. During this time shortwave heating by ozone is negligible in polar regions, indicating that the specification of the ozone distribution (fixed ozone versus interactively coupled ozone) has only a minor impact on simulated temperatures in the polar stratosphere.

The pronounced "cold pole" problem seen in SOCOLvs2 is associated with a stronger polar vortex and a delayed breakdown of the vortex, both of which affect the simulation of the Antarctic ozone hole. This model behavior is reflected in the seasonal cycle of the zonal winds and a delayed transition from westerlies to easterlies at $60^{\circ} \mathrm{S}$ (Fig. 3). In agreement with the improved representation of stratospheric temperatures in SOCOLvs3 (Fig. 2, bottom right), the timing of the simulated zonal wind reversal in SOCOLvs 3 compares very well with ERA-40 and ERA-Interim (Fig. 3).

Stratospheric polar temperatures during winter and spring as well as their interannual variability are largely determined by the forcing of planetary waves that propagate from the troposphere into the stratosphere. Newman et al. (2001) have shown that the polar temperatures in late winter at $50 \mathrm{hPa}$ are well correlated with the meridional heat flux at $100 \mathrm{hPa}$ in the middle of winter. The meridional heat flux at $100 \mathrm{hPa}$ is proportional to the vertical component of the Eliassen-Palm (EP) flux entering the stratosphere and therefore a measure of transferred wave energy. Figure 4 compares the model results for SOCOLvs2 and SOCOLvs3 with the ERA-40 and NCEP reanalyses. The slope and the intercept of the regression lines (see legend of Fig. 4) provide additional information about the model behavior: the slope indicates the stratospheric temperature response to a unit amount of resolved tropospheric wave forcing. The intercept indicates the polar stratospheric temperature if no resolved wave-driving were present. In the NH SOCOLvs2 shows the best performance

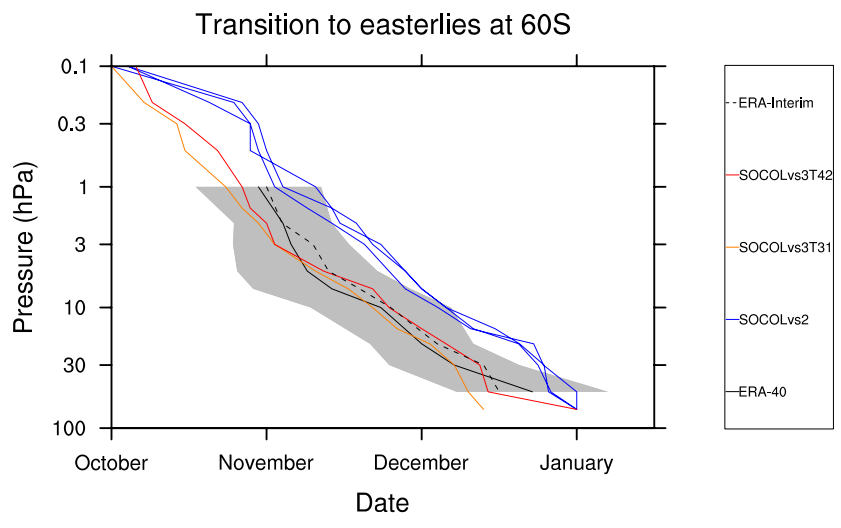

Fig. 3. Timing of transition from westerlies to easterlies (indicating the breakdown of the Antarctic vortex) at $60^{\circ} \mathrm{S}$ for ERA-40 (solid black line), ERA-Interim (dashed black line), SOCOLvs2 (blue lines), SOCOLvs3 T31 horizontal resolution (orange line), and SOCOLvs3 T42 horizontal resolution (red line). Grey shading indicates ERA-40 plus and minus 1 standard deviation about the climatological mean (1980-1999).

of the three model versions in terms of slope and intercept, with a small vertical offset reflecting the simulated cold bias (Fig. 2). The simulated temperature response per unit of wave forcing is in good agreement with ERA-40. The results for SOCOLvs3 show a displacement to the right, suggesting that a larger amount of tropospheric wave forcing is required in SOCOLvs 3 to simulate stratospheric temperatures comparable to ERA-40. However, the linear fit parameters of both model versions, SOCOLvs2 and SOCOLvs3, still lie within the $95 \%$ confidence interval of ERA-40 (not shown).

In the SH the model results show larger variation, especially with respect to the slope of the regression lines. Again SOCOLvs 2 is displaced below the reanalysis, reflecting a small cold temperature bias. In terms of the simulated temperature response to the wave forcing, SOCOLvs2 shows an underestimated sensitivity, while SOCOLvs3, especially the T42 version, overestimates the temperature response. SOCOLvs3 in T31 resolution compares best with ERA-40.

The seasonal temperature variations at the tropical cold point tropopause are a key driver for the entry of water vapor from the troposphere into the stratosphere. To facilitate the comparison with the reanalysis data we show the mean annual cycle of equatorial temperatures at $100 \mathrm{hPa}$ (Fig. 5a) instead of the cold point temperatures. All SOCOL model versions assessed are able to reproduce the phase of the seasonal cycle. The simulated winter and spring temperatures also compare very well with ERA-Interim, while ERA-40 is $1.5-2 \mathrm{~K}$ warmer throughout the year. In general, ERAInterim data provide a more reliable representation of the stratosphere (Monge-Sanz et al., 2007) and are regarded to be the more reliable data product. SOCOL generally underestimates the summer temperature maximum by $1-2 \mathrm{~K}$, with SOCOLvs3 in T42 horizontal resolution showing the best 

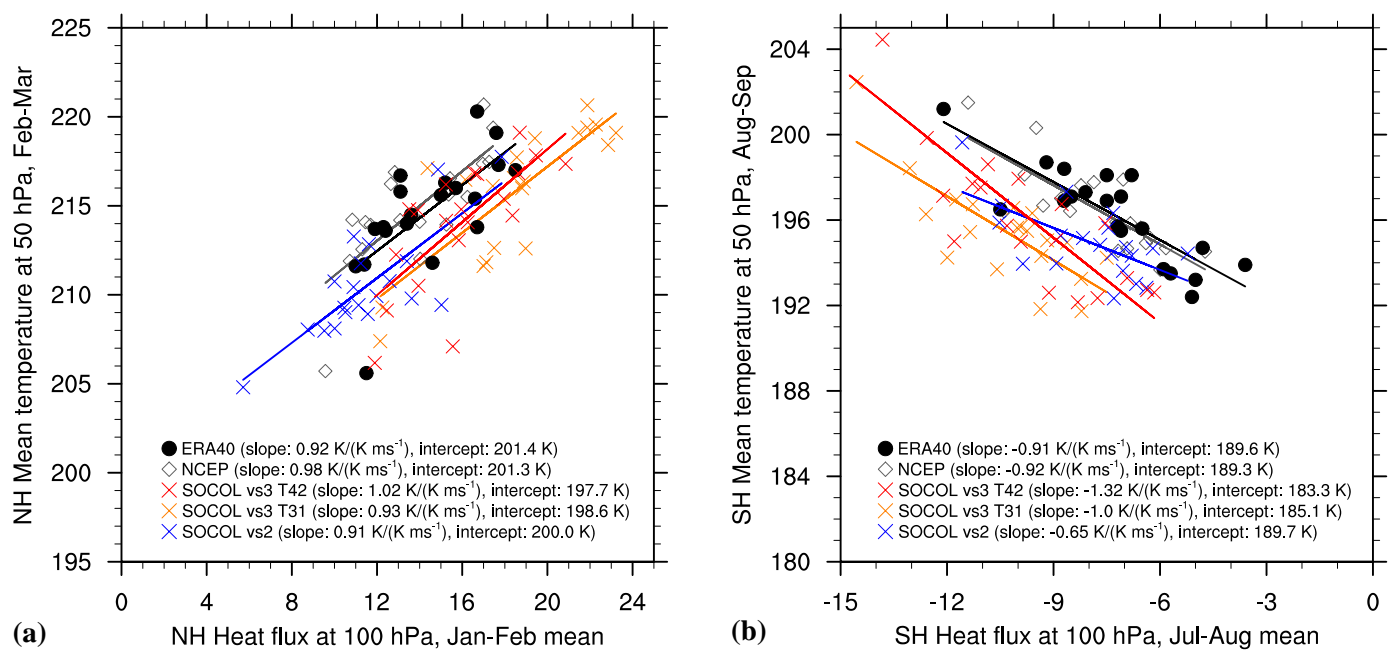

Fig. 4. (a) Heat fluxes $\left(\overline{v^{\prime} T^{\prime}}\right)\left[\mathrm{K} \mathrm{ms}^{-1}\right]$ at $100 \mathrm{hPa}$ (averaged over $40^{\circ} \mathrm{N}$ to $80^{\circ} \mathrm{N}$ for January and February) versus temperatures $[\mathrm{K}]$ at $50 \mathrm{hPa}$ (averaged over $60^{\circ} \mathrm{N}$ to $90^{\circ} \mathrm{N}$ for February and March). Shown are $20 \mathrm{yr}$ from 1980 to 1999 for SOCOLvs3 T42 (red), SOCOLvs3 (orange), SOCOLvs2 (blue), ERA-40 (black) and NCEP (grey) reanalyses. (b) Same for Southern Hemisphere with heat fluxes at $100 \mathrm{hPa}$ averaged over $40^{\circ} \mathrm{S}$ to $80^{\circ} \mathrm{S}$ for July and August versus temperatures at $50 \mathrm{hPa}$ averaged over $60^{\circ} \mathrm{S}$ to $90^{\circ} \mathrm{S}$ for August and September.
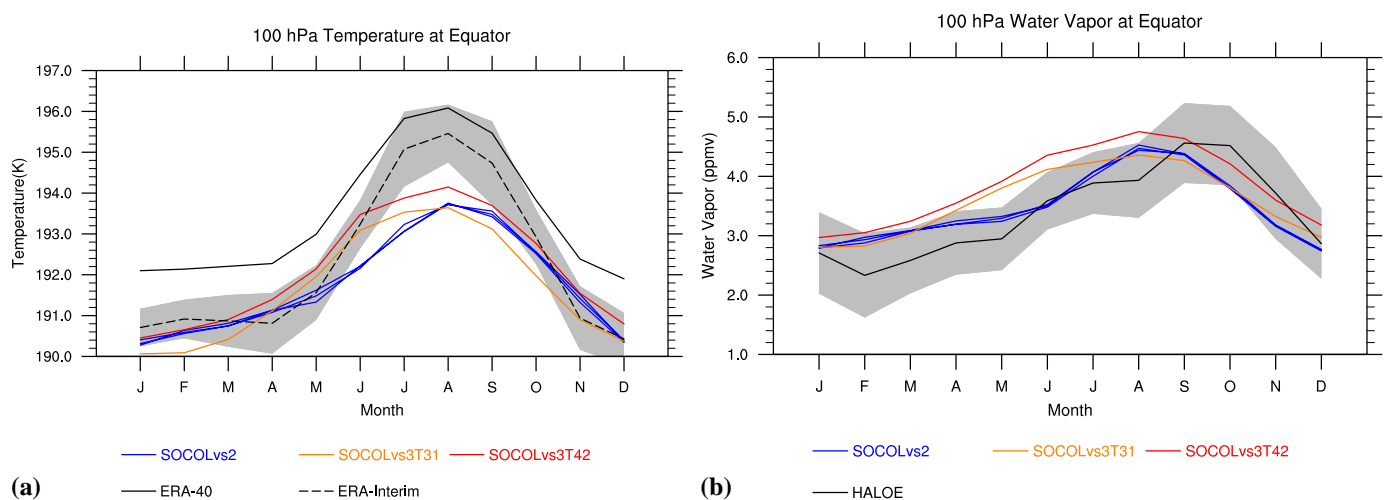

Fig. 5. Seasonal variation of the climatological mean temperature (a) and $\mathrm{H}_{2} \mathrm{O}$ (b) at $100 \mathrm{hPa}$ at the Equator, for SOCOLvs2 (blue lines), SOCOLvs3 T31 horizontal resolution (orange line), SOCOLvs3 T42 horizontal resolution (red line), ERA-40 (solid black line) and ERAInterim (dashed black line, grey shading $\pm 1 \sigma, 1992-2001$ ), and HALOE observations (solid black line, grey shading $\pm 1 \sigma, 1992-2001$ ).

agreement with ERA-Interim. As a consequence of the temperature increase at the equatorial tropopause, SOCOLvs3 simulates higher water vapor mixing ratios at this level than SOCOLvs2, especially during early summer (Fig. 5b). Although both SOCOL versions simulate the maximum water vapor mixing ratios one month earlier than observed, the absolute values compare very well with HALOE. Minimum water vapor mixing ratios, however, are overestimated by SOCOL. Gettelman et al. (2009) (see also SPARC, 2010) examined the dehydration process at the tropical tropopause and the role of the cold point temperature by calculating the correlation between the saturation water vapor mixing ratio at cold point temperature $\left(Q_{\mathrm{SAT}}\left(T_{\mathrm{CPT}}\right)\right)$ and the water vapor mixing ratio at or just above the tropical tropopause. The respective values for all SOCOL versions indicate higher mean saturation levels (about $80 \%$ ) of air masses entering the stratosphere than those derived from ERA-Interim/HALOE (about $70 \%$ ).

\subsection{Methane}

The stratospheric methane $\left(\mathrm{CH}_{4}\right)$ distribution is largely controlled by methane oxidation and transport. Due to its long photochemical lifetime, methane is an excellent tracer of atmospheric circulation.

Figure 6 shows climatological mean mixing ratios of methane from SOCOLvs2 and vs3 (T31, T42) and HALOE observations (Grooß and Russell, 2005). For Fig. $6 \mathrm{CH}_{4}$ on equivalent latitudes has been used. In the middle and upper tropical and subtropical stratosphere SOCOLvs3 shows a general reduction of $\mathrm{CH}_{4}$ compared to the previous model version (Fig. 6b), resulting in better agreement with the 
(a) $\mathrm{CH}_{4} 80 \mathrm{~N}$ MAR

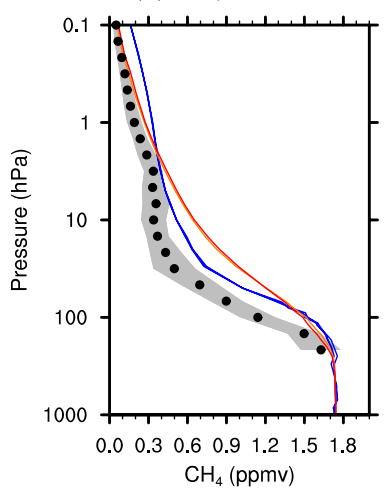

(d) $\mathrm{CH}_{4} 50 \mathrm{hPa}$ MAR

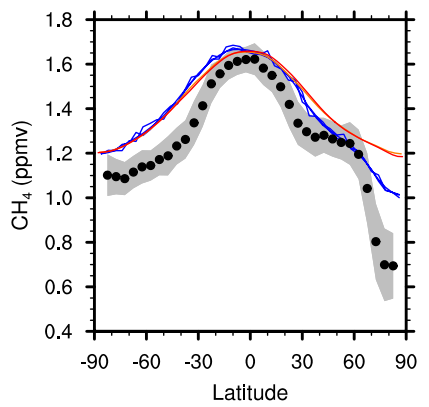

(b) $\mathrm{CH}_{4}$ Equator MAR

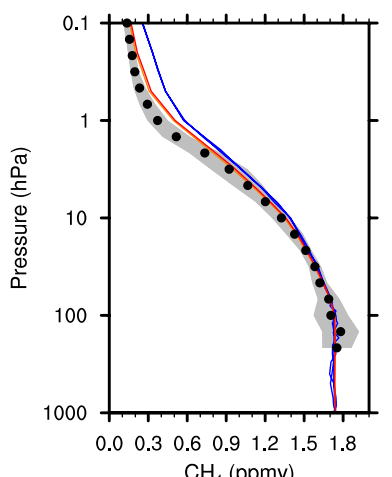

(c) $\mathrm{CH}_{4} 80 \mathrm{~S}$ OCT

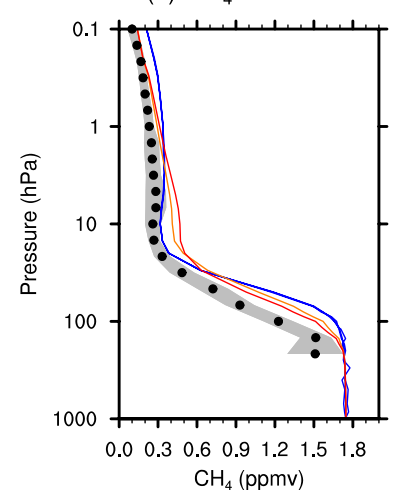

(e) $\mathrm{CH}_{4} 50 \mathrm{hPa}$ OCT

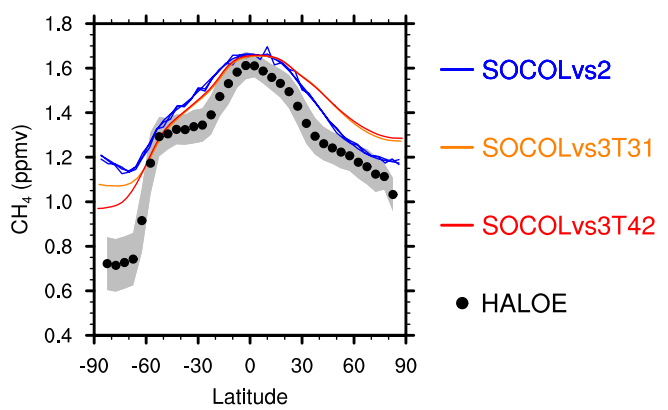

Fig. 6. Comparison of climatological (1992-2001) zonal-mean $\mathrm{CH}_{4}$ mixing ratios (ppmv) from SOCOL and from HALOE for the same equivalent latitude. Upper panels: vertical profiles at (a) $80^{\circ} \mathrm{N}$, March; (b) $0^{\circ}$, March; and (c) $80^{\circ} \mathrm{S}$, October. Lower panels: meridional cross-section at $50 \mathrm{hPa}$ in (d) March and (e) October. The grey shaded areas indicate the HALOE standard deviation $( \pm 1 \sigma)$.

HALOE measurements. A slower residual circulation in SOCOLvs3 (see also Sect. 5.3), and therefore a more efficient $\mathrm{CH}_{4}$ oxidation during ascent, can explain this finding. In the lower-stratosphere northern extratropics, SOCOLvs3 generally simulates higher $\mathrm{CH}_{4}$ mixing ratios than vs2. A similar difference pattern in the lower stratosphere is also found for $\mathrm{N}_{2} \mathrm{O}$ and the CFCs.

Remarkable differences in the simulated $\mathrm{CH}_{4}$ distribution of both model generations also occur in the southern polar vortex (Fig. 6e), with SOCOLvs3 showing significantly lower $\mathrm{CH}_{4}$ values than SOCOLvs2 and, therefore, a much better agreement with the HALOE observations. This improvement is most pronounced in the T42 simulation. The high $\mathrm{CH}_{4}$ concentrations in SOCOLvs 2 are most probably related to the semi-Lagrangian transport scheme, which is known to be excessively diffusive in the presence of sharp gradients; i.e., there is an artificial horizontal diffusion of $\mathrm{CH}_{4}$-rich air masses from mid-latitudes into the polar vortex. Further artifacts from the application of the mass fixer can also not be excluded. Possible reasons for the remaining high $\mathrm{CH}_{4}$ bias in SOCOLvs3 are too-strong horizontal mixing across the vortex edge and/or too-weak downward transport in the high latitudes. It should be mentioned that most of the CCMVal models showed a similar behavior to SOCOLvs3 in the Southern Hemisphere polar spring (see
Fig. 5 of Eyring et al., 2006). Due to limited observations in polar regions and the large year-to-year variability in the Arctic, there is also considerable uncertainty associated with the HALOE data, which could be partly responsible for the apparently large discrepancy at latitudes north of $70^{\circ} \mathrm{N}$.

\subsection{Water vapor}

There are two sources of $\mathrm{H}_{2} \mathrm{O}$ in the stratosphere: upward transport from the troposphere and $\mathrm{CH}_{4}$ oxidation in the stratosphere. The amount of tropospheric water vapor entering the stratosphere is directly related to the cold point temperature at the tropical tropopause. The annual cycle in the tropical tropopause temperature (Fig. 5a) generates a corresponding signal in the tropical water vapor, which slowly propagates upward in the tropical pipe (the so-called water vapor "tape recorder"; Mote et al., 1996). The "tape recorder" signal can be used to assess both the ascent rate in the tropical pipe by the residual circulation and the mixing with mid-latitude air.

Figure 7 compares mean vertical profiles of $\mathrm{H}_{2} \mathrm{O}$ at different latitudes, and latitudinal distributions at $50 \mathrm{hPa}$ from both model versions and HALOE measurements. As a direct consequence of the higher (by more than $0.5 \mathrm{~K}$ ) and more persistent (more than twice as long) temperature maximum at the tropical tropopause (Fig. 5a), SOCOLvs3 shows 
(a) $\mathrm{H}_{2} \mathrm{O} 80 \mathrm{~N}$ MAR

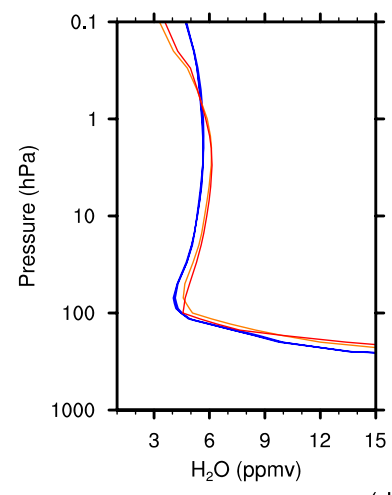

(d) $\mathrm{H}_{2} \mathrm{O} 50 \mathrm{hPa}$ MAR

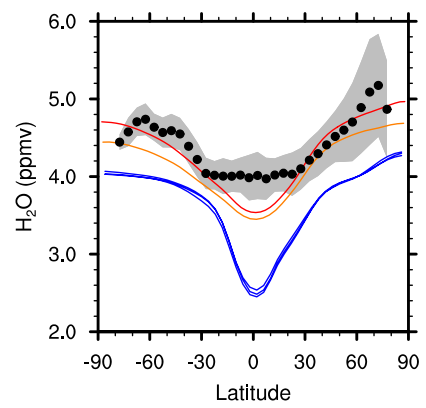

(b) $\mathrm{H}_{2} \mathrm{O}$ Equator MAR

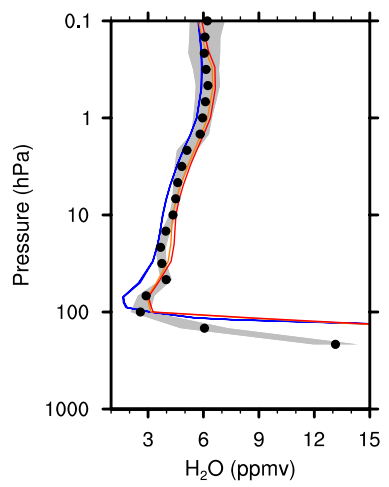

(c) $\mathrm{H}_{2} \mathrm{O} 80 \mathrm{~S} \mathrm{OCT}$

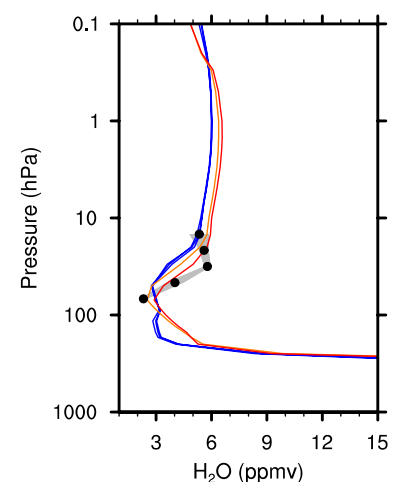

(e) $\mathrm{H}_{2} \mathrm{O} 50 \mathrm{hPa}$ OCT

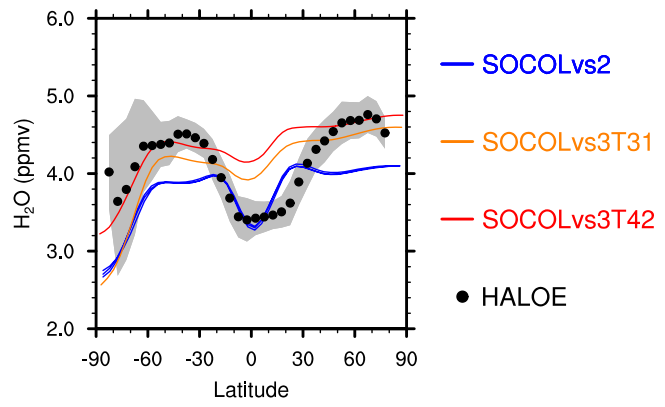

Fig. 7. Same as in Fig. 6 but for water vapor in ppmv.

a general increase in stratospheric water vapor mixing ratios compared to vs2. Another reason is the slowdown of the Brewer-Dobson circulation, which leads to enhanced water vapor production by $\mathrm{CH}_{4}$ oxidation. In agreement with a stronger warming of the tropical tropopause (Fig. 5a), the increase in stratospheric water vapor is more pronounced in the T42 simulation.

SOCOLvs3 compares well with observations throughout the stratosphere with the exception of the lower tropical stratosphere. Compared to HALOE, SOCOLvs3 is slightly too moist (up to $10 \%$ ) but agrees well with MIPAS measurements, which are around $10 \%$ moister than HALOE (Milz et al., 2009; not shown). In the lower tropical stratosphere, the model bias depends on pressure level and season. The reason is obvious from the water vapor tape recorder displayed in Fig. 8: while the seasonal water vapor cycle at the tropical tropopause at $100 \mathrm{hPa}$ is well captured by the model, the upward propagation of the tape recorder signal is too fast in all model versions. At $50 \mathrm{hPa}$, the simulated annual cycle is 4.5 months out of phase compared to HALOE. The HALOE tape recorder signal propagates with a phase speed of about $10 \mathrm{~km} \mathrm{yr}^{-1}$, while the propagation speed in SOCOL is twice as fast, with values of $21.8 \mathrm{~km} \mathrm{yr}^{-1}$ in SOCOLvs2 and $18.5 \mathrm{~km} \mathrm{yr}^{-1}\left(19.9 \mathrm{~km} \mathrm{yr}^{-1}\right)$ in SOCOLvs3T31 (T42). The clear overestimation of the upward transport in the tropical pipe shown by the tape recorder suggests a residual circulation that is too strong in SOCOL. Struthers et al. (2009) found that the stratospheric air in SOCOLvs2 is $1-2.5 \mathrm{yr}$ too young. Compared with SOCOLvs2, the tape recorder indicates a slowdown of the residual circulation in vs3 by $10-$ $15 \%$, but the vertical propagation is still too fast. The problem of a too-fast upward transport in the tropical pipe seems to be a common problem of ECHAM-based CCMs (see e.g. Fig. 8 of Eyring et al., 2006; SPARC, 2010). With respect to the decay of the amplitude with height due to mixing processes, i.e., the vertical attenuation of the tape recorder signal, SOCOLvs2 shows a too-rapid decay in the middle stratosphere, indicating a strong tropical-extratropical mixing. SOCOLvs3 agrees slightly better with the HALOE observations.

\subsection{Chlorine species/HCl}

Figure 9 shows simulated total inorganic plus organic chlorine $\left(\mathrm{CCl}_{\mathrm{y}}\right)$, total inorganic chlorine $\left(\mathrm{Cl}_{\mathrm{y}}\right)$ and reactive chlorine $\left(\mathrm{ClO}_{\mathrm{x}}\right)$ as well as simulated and observed $\mathrm{HCl}$ for the 1990s. The improvement in simulated $\mathrm{CCl}_{\mathrm{y}}$ due to the advanced advection scheme of Lin and Rood (1996) described in Sect. 4 is clearly visible: while SOCOLvs 2 shows an unrealistic $\mathrm{S}$-shape in the vertical $\mathrm{CCl}_{\mathrm{y}}$ profiles with a minimum around $20 \mathrm{~km}$ during polar winter and early spring, vs 3 shows the expected $\mathrm{CCl}_{\mathrm{y}}$ decrease with height and latitude; i.e., older air masses contain less $\mathrm{CCl}_{\mathrm{y}}$ in accordance with increasing CFC surface mixing ratios until the early 1990s.

The improved conservation of the $\mathrm{CCl}_{\mathrm{y}}$ family leads also to an improved representation of $\mathrm{HCl}$ in the model. In the 


\section{Water Vapor anomaly time height sections (averaged from $10 \mathrm{~S}$ to $10 \mathrm{~N}$ )}

(a) HALOE

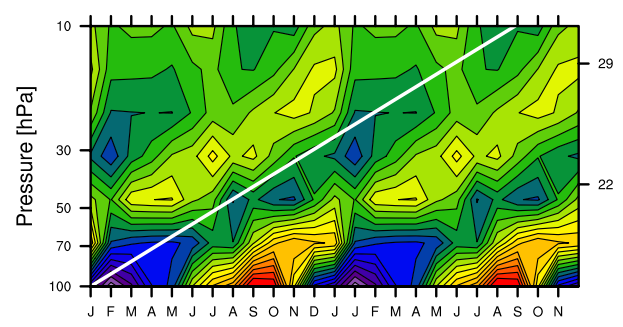

(c) SOCOLvs3T31

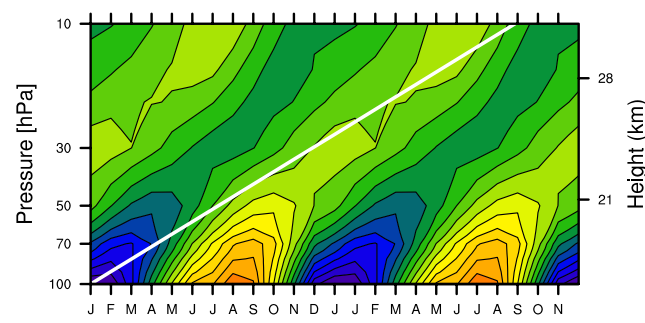

(b) SOCOLvs2

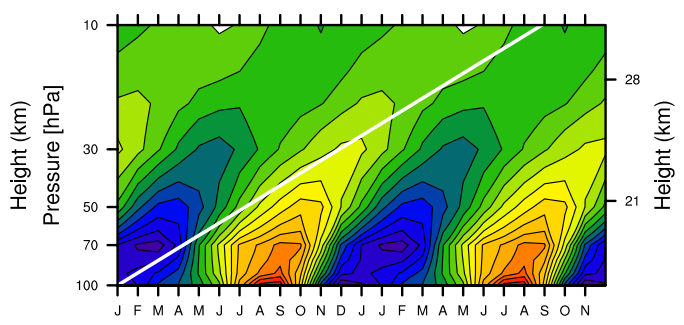

(d) SOCOLvs3T42

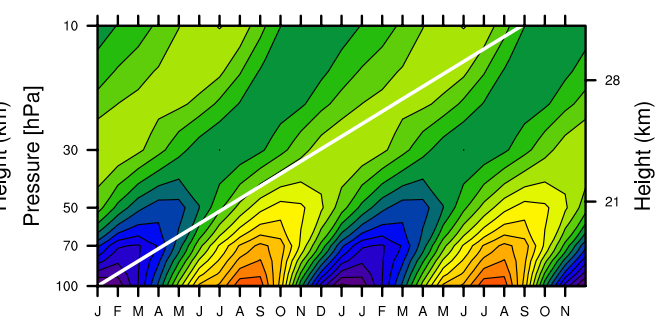

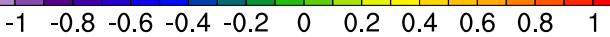

Fig. 8. Averaged (1992-2001) time-height sections of water vapor mixing ratio shown as the deviation from the mean profile, averaged between $10^{\circ} \mathrm{N}$ and $10^{\circ} \mathrm{S}$ for (a) HALOE, (b) SOCOLvs2, (c) SOCOLvs3 T31, and (d) SOCOLvs3 T42. Two consecutive (identical) cycles are shown. The white line indicates the phase speed of the HALOE tape recorder signal.

lower stratosphere $(50 \mathrm{hPa}) \mathrm{SOCOLvs} 3$ compares well with HALOE $\mathrm{HCl}$ measurements except at southern high latitudes in winter and spring (Fig. 9c and e). This is related to a downward shift of the $\mathrm{HCl}$ and $\mathrm{Cl}_{\mathrm{y}}$ profiles inside the polar vortex (Fig. 9c) in SOCOLvs3 compared to vs2. In the middle stratosphere, the model bias is reduced, but simulated $\mathrm{HCl}$ remains too high (Fig. 9b). This problem might be related to an incorrect chlorine partitioning: in the middle stratosphere, simulated $\mathrm{ClONO}_{2}$ is underestimated by up to $40 \%$ compared to retrievals of the Cryogenic Limb Array Etalon Spectrometer (CLAES) (Roche et al., 1993, 1994) (not shown). This may partly be explained by an underestimation of stratospheric $\mathrm{NO}_{\mathrm{x}}$ resulting in a too-slow $\mathrm{ClONO}_{2}$ formation through the reaction of $\mathrm{ClO}$ with $\mathrm{NO}_{2}$.

For reactive chlorine species $\left(\mathrm{ClO}_{\mathrm{x}}\right)$, the difference pattern between the two model versions is more complicated. In the tropical middle and upper stratosphere, $\mathrm{ClO}_{\mathrm{x}}$ simulated by SOCOLvs3 is remarkably higher than for vs2 (Fig. 9b). This can be explained by a general decrease of stratospheric $\mathrm{NO}_{\mathrm{x}}$ (and $\mathrm{NO}_{\mathrm{y}}$ ) in vs 3 compared to SOCOLvs2 (not shown), resulting in a slower $\mathrm{ClO}_{\mathrm{x}}$ deactivation by the reaction of $\mathrm{ClO}$ with $\mathrm{NO}_{2}$. In the southern polar vortex, $\mathrm{ClO}_{\mathrm{x}}$ is almost double in winter (not shown), but lower in spring (Fig. 9c and e). The former can be explained by the increase of $\mathrm{Cl}_{\mathrm{y}}$ in the same region, while the latter could be the effect of substantially lower ozone concentrations in late August and September leading to a higher conversion of $\mathrm{Cl}$ to the reservoir gas $\mathrm{HCl}$, as there is less ozone left to react with.
Increasing the model resolution from T31 to T42 significantly affects the chlorine concentration in the polar vortex. Both $\mathrm{Cl}_{\mathrm{y}}$ and $\mathrm{HCl}$ are increased for $\mathrm{T} 42$, which is probably the effect of a more efficient transport barrier at the vortex edge and less horizontal mixing. In contrast, $\mathrm{ClO}_{\mathrm{x}}$ concentrations in the southern polar vortex are hardly influenced (Fig. 9a and d), probably because of two compensating effects: while $\mathrm{Cl}_{\mathrm{y}}$ is increased, the chlorine activation on PSC II is decreased due to a warmer polar vortex. In the northern polar vortex, the T42 model version shows a $\mathrm{ClO}_{\mathrm{x}}$ reduction of $40-80 \%$, as chlorine activation on STSs is substantially reduced due to the higher temperatures.

\subsection{Ozone}

Figure 10 shows mean vertical profiles of $\mathrm{O}_{3}$ at different latitudes as well as latitudinal distributions at $50 \mathrm{hPa}$ from both model versions and measurements. At $50 \mathrm{hPa}$, the differences in simulated ozone mixing ratios between both model versions are rather small, with SOCOLvs3 showing slightly higher ozone values. The horizontal resolution has almost no impact on the simulated ozone distribution in SOCOLvs3. The largest differences occur in the northern high latitudes, especially during spring, where SOCOLvs3 simulates significantly higher values than vs2 (Fig. 10a and d). In SH spring (Fig. 10c) the most pronounced differences between both model versions occur in the lower stratosphere, with SOCOLvs2 showing an unrealistic $\mathrm{S}$-shape profile, which is 
(a) $80 \mathrm{~N}$ MAR

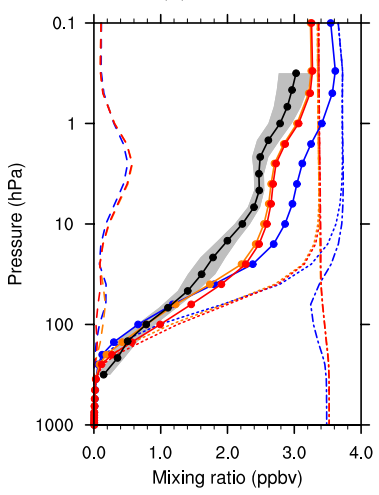

(d) 50hPa MAR
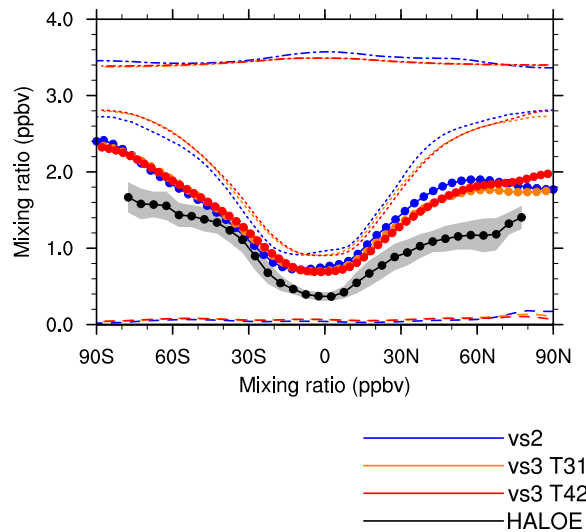

(b) Equator MAR

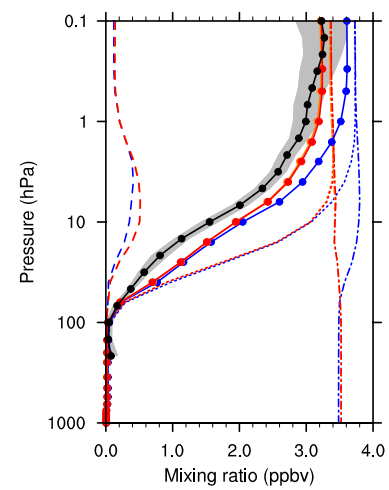

(c) $80 \mathrm{~S} \mathrm{OCT}$

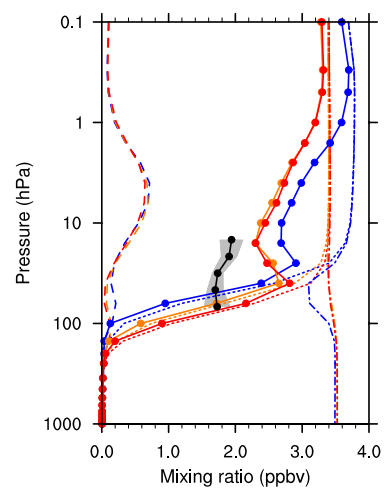

(e) $50 \mathrm{hPa}$ OCT

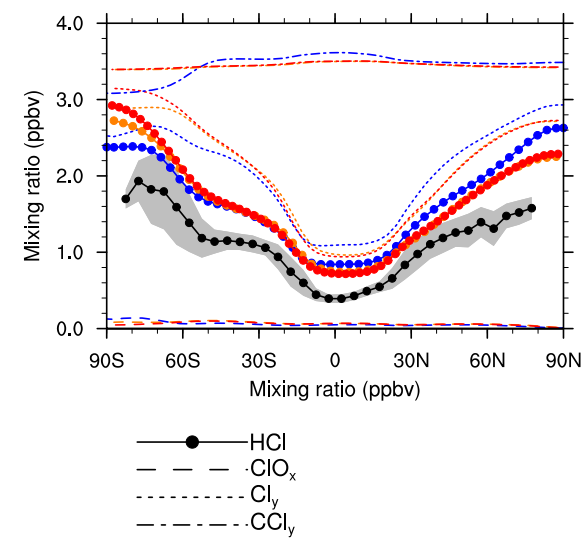

Fig. 9. Same as in Fig. 6 but for various chlorine species in ppbv. Dashed lines: odd chlorine $\left(\mathrm{ClO}_{\mathrm{x}}\right)$; dotted lines: total inorganic chlorine $\left(\mathrm{Cl}_{\mathrm{y}}\right)$; dash-dotted lines: total inorganic plus organic chlorine $\left(\mathrm{CCl}_{\mathrm{y}}\right)$; filled circles: $\mathrm{HCl}$.

directly related to the simulated distribution of the chlorine species (Fig. 9c). This feature is no longer apparent in SOCOLvs3.

In the tropical stratosphere SOCOLvs3 (T31, T42) compares very well with HALOE observations (Fig. 10b), but slightly $(\sim 5 \%)$ overestimates the observations at high altitudes. In the lower stratosphere, simulated ozone in SOCOLvs 3 is positively biased, but within the standard deviation of the observations in most regions (Fig. 10d and e).

Finally, Fig. 11 shows monthly zonal-mean total ozone for the 1980-1989 and 1990-1999 periods. While SOCOLvs2 was not able to reproduce the seasonal cycle in tropical and mid-latitudinal regions, the seasonal variability in SOCOLvs3 agrees well with the observations. The improvement of the seasonal variability of total ozone in vs 3 is a direct effect of the substantial changes of ozone in the lowermost stratosphere due to the advection scheme of Lin and Rood (1996) as described above. The timing of the Antarctic ozone hole (middle of September instead of beginning of October) is now in good agreement with observations, whereas the spring maximum in southern mid-latitudes occurs about 2 months earlier than observed. The ozone hole in SOCOLvs3 is clearly too deep, which is a degradation compared to SOCOLvs2. However, the higher total ozone values in vs2 during the ozone hole period are not the result of an overall better model performance, but related to the unrealistic high ozone concentrations in the polar lowermost stratosphere (Fig. 10c). The vs3 model bias in total ozone in the polar region is less pronounced in the T42 simulation. In northern polar winter and spring, all model versions are negatively biased, with SOCOLvs3 in T42 horizontal resolution again comparing best with observations. In the high latitudes of both summer hemispheres, SOCOLvs3 shows a reduced model bias in total ozone. Both model versions reproduce the observed negative trend in total column ozone at midand high latitudes. Overall, the representation of total column ozone has clearly improved from SOCOLvs 2 to vs 3 , with the T42 simulation showing a slightly better agreement with observations than the T31 simulation. For a better comparison, Fig. 12 shows the differences in monthly zonal-mean total ozone between SOCOL and NIWA for the 1980-1989 and 1990-1999 periods.

\subsection{Grading}

We illustrate the benefits of the new model version by applying the grading technique proposed by Waugh and 
(a) $\mathrm{O}_{3} 80 \mathrm{~N}$ MAR

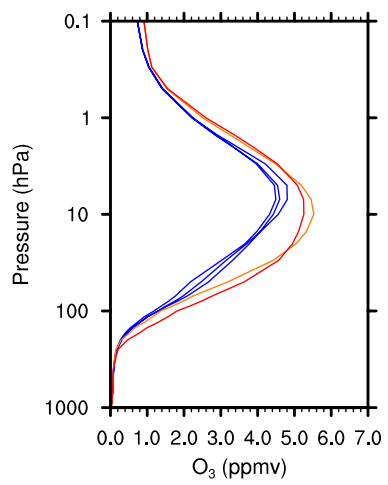

(d) $\mathrm{O}_{3} 50 \mathrm{hPa}$ MAR

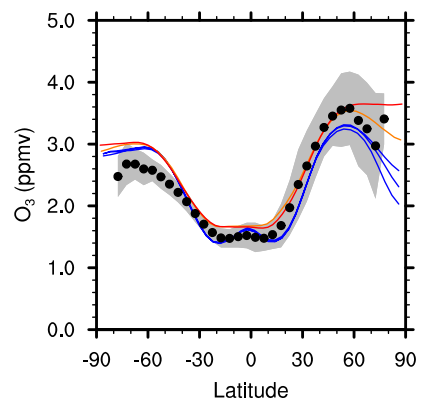

(b) $\mathrm{O}_{3}$ Equator MAR

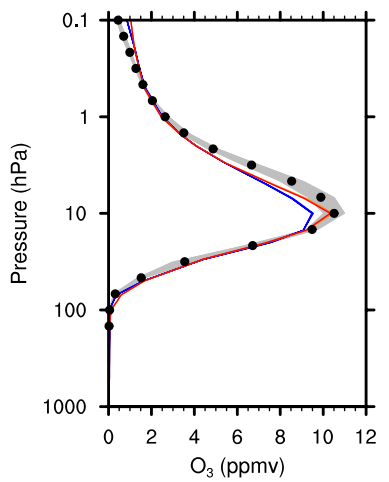

(c) $\mathrm{O}_{3} 80 \mathrm{~S} \mathrm{OCT}$

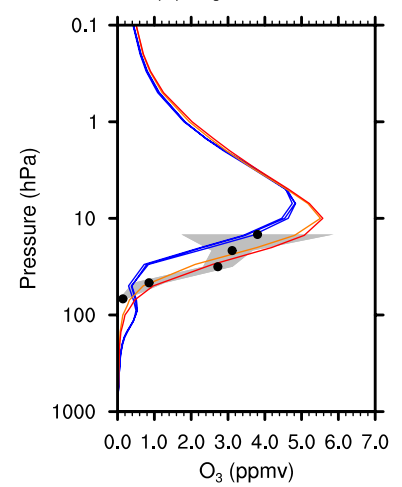

(e) $\mathrm{O}_{3} 50 \mathrm{hPa}$ OCT

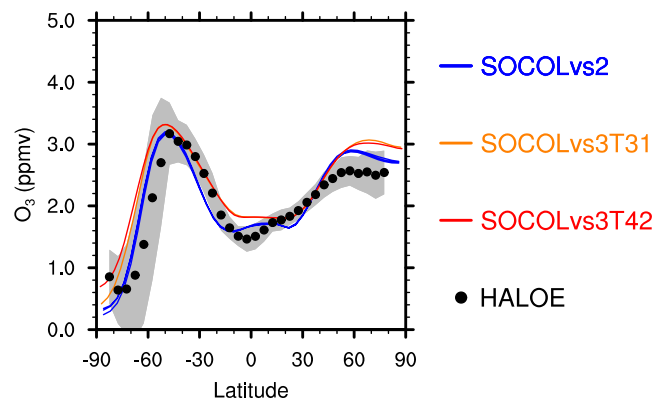

Fig. 10. Same as in Fig. 6 but for ozone in ppmv.

Eyring (2008). This method is based on the comparison of several quantities extracted from the model output with observations, taking into account the internal variability and uncertainties of the observational data. These model validation metrics provide a quick overview on the progress in model development. However, it should be noted that there has also been criticism (e.g., Grewe and Sausen, 2009) pointing to specific weaknesses in this method concerning statistical limitations of the grading method. Furthermore, as stated by Butchart et al. (2011), metrics themselves provide only limited information on the quality of simulated physical processes and, therefore, need to be combined with a comprehensive analysis of model results, as was done in the previous sections. Notwithstanding these limitations, similar validation metrics were also applied in SPARC (2010), exploiting however a more complicated set of parameters and procedures. Reproducing all metrics from SPARC (2010) would go beyond the scope of this paper. We therefore calculate the grades $(g)$ using the original Eq. (4) of Waugh and Eyring (2008) in the following form:

$g=\max \left\{0,\left[1-\frac{\operatorname{abs}\left(f_{\mathrm{m}}-f_{\mathrm{obs}}\right)}{3 s_{\mathrm{obs}}}\right]\right\}$,

where $f_{\mathrm{m}}$ and $f_{\mathrm{obs}}$ are the model and observational values of each considered quantity and $s_{\mathrm{obs}}$ is the interannual standard deviation of the observations. The set of considered quantities consists of 16 variables listed in Table 2 of Waugh and
Eyring (2008). The observed climatological mean and interannual standard deviation of considered quantities were calculated using ERA-40 (Uppala et al., 2005) for the period 1980-1999 and HALOE UARS data (Grooß and Russell, 2005) for the period 1991-2000, while the mean ages data were taken from Eyring et al. (2006). The grading marks for all considered quantities, as well as the overall model grade defined as the mean over all grades, are shown in Fig. 13 for SOCOLvs2 as well as SOCOLvs3 with horizontal truncation at T31 and T42. As described in Sect. 2 the main difference between the two model versions is of the application of MA-ECHAM5 instead of MA-ECHAM4 as the core GCM and the flux-form semi-Lagrangian transport scheme (Lin and Rood, 1996) instead of a hybrid transport scheme (Zubov et al., 1999). The chemical module remains the same. The application of the new transport scheme leads to a substantial improvement of the model performance in the simulation of the total inorganic chlorine and methane over the southern high latitudes in October (Cly-SP and $\mathrm{CH}_{4}-\mathrm{SP}$ ) as well as in the speed of the tape recorder (Tape-c), which is reduced by $10 \%$. Surprisingly, the application of a more accurate and less diffusive transport scheme did not help to improve the quality of the mean age of air. The model grades for these quantities remain almost the same for both horizontal resolutions as in the version 2. However, it should be noted that this discrepancy might be related to methodical reasons, since two slightly different passive tracer diagnostics were 

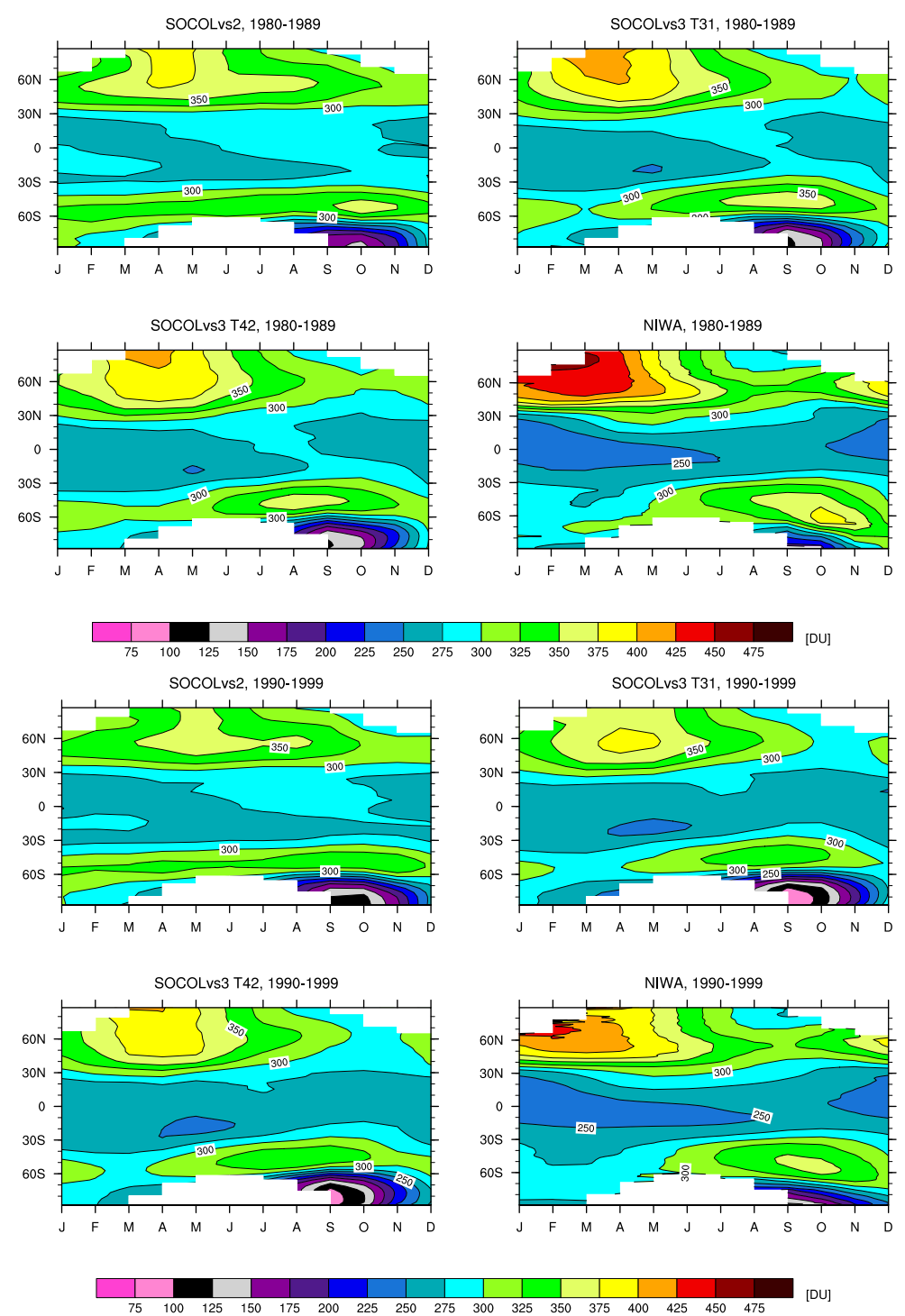

Fig. 11. Zonal mean of total ozone in DU averaged over the two 10 yr periods, 1980-1989 (upper four panel) and 1990-1999 (lower four panel), for SOCOLvs2, SOCOLvs3 in T31 and T42 horizontal resolution, and NIWA observational data.

used for calculating the age of air in SOCOLvs2 and SOCOLvs3, respectively. Within SOCOLvs3 we used a passive $\mathrm{CO}_{2}$ tracer. As a lower boundary condition we prescribed monthly and zonal-mean $\mathrm{CO}_{2}$ mixing ratios including a linear trend of $1.5 \mathrm{ppmv} \mathrm{yr}^{-1}$ together with a climatological but latitudinally varying seasonal cycle (Hall and Prather, 1993). In SOCOLvs2 we applied a similar procedure, but instead of a seasonally varying $\mathrm{CO}_{2}$-like tracer we used a passive tracer with a global mean, linearly increasing lower boundary condition.

The application of the new GCM core improved the representation of polar temperatures in the lower stratosphere, while the representation of the heat flux in the $\mathrm{NH}$ remains almost unchanged and got even worse in the SH. The overall grade demonstrates the slightly improved performance of the new model version, confirming that the model development is heading in the right direction. However, it is not clear whether the change of an overall grade from $\sim 0.55$ to $\sim 0.65$ is significant (Grewe and Sausen, 2009). Furthermore, the overall grade might change with the chosen subset of parameters and diagnostics. Future efforts should aim at the improvement of the performance of SOCOL in the tropical lower stratosphere, where the representation of the temperature and water vapor distribution, as well as the mean age of air, are still not satisfactory. As was mentioned by Butchart et al. (2011), the grading simply illustrates the model performance, but it does not provide substantial information regarding missing or under-represented processes, so that a more careful analysis of the model runs is necessary to define which part of the model can and should be improved. 

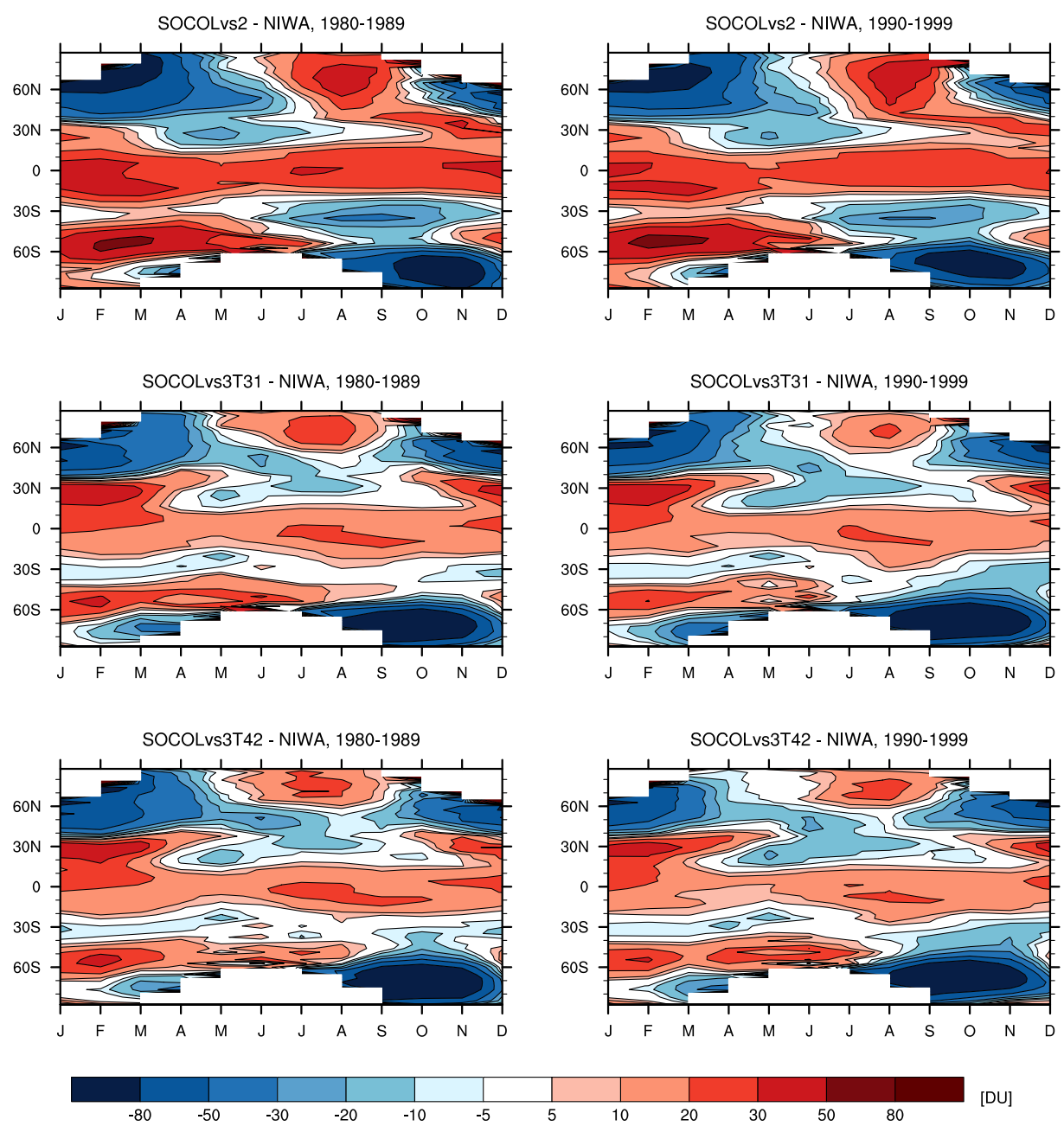

Fig. 12. Differences of zonal-mean total ozone between the different SOCOL simulations and NIWA observations averaged over the two 10 yr periods, 1980-1989 (left) and 1990-1999 (right).

\section{Conclusions}

This paper presents the third generation of the coupled chemistry-climate model SOCOL. Compared to the previous model version, the underlying general circulation model has been updated from MA-ECHAM4 to MA-ECHAM5, and the former hybrid advection algorithm has been replaced by a mass-conserving and shape-preserving flux-form semi-Lagrangian scheme. In contrast to its predecessors SOCOLvs 3 is now fully parallelized and can be used on multiprocessor machines. Stratospheric model dynamics and simulated distributions of chemical trace species have been evaluated against various observational datasets and previous model versions. The previous model version SOCOLvs2 was extensively validated within CCMVal-2 (SPARC, 2010). In the following we summarize the model performance of SOCOLvs2 and SOCOLvs3 with respect to stratospheric dynamics, transport, and ozone chemistry. Statements in quotes refer to SOCOLvs2 (SPARC, 2010):
"SOCOLvs2 simulates the stratospheric mean state in winter and spring well in both hemispheres although there are significant biases in the SH lower stratosphere in spring. Stratospheric variability in the model is weak, perhaps linked to the small amounts of heat flux at $100 \mathrm{hPa}$. In the $\mathrm{SH}$ the relationship between heat flux and lower stratospheric temperatures is well simulated".

With respect to the mean stratospheric state in winter, SOCOLvs3 performs similarly to SOCOLvs2. Major differences occur in the upper stratosphere, where SOCOLvs3 simulates higher temperatures than SOCOLvs2, a consequence of the updated shortwave radiation scheme. In spring, however, SOCOLvs3 shows a clearly improved performance in the lower stratosphere, especially in the SH. Furthermore, stratospheric variability in SOCOLvs3 is enhanced in both hemispheres. This may be related to larger tropospheric wave-forcing. 


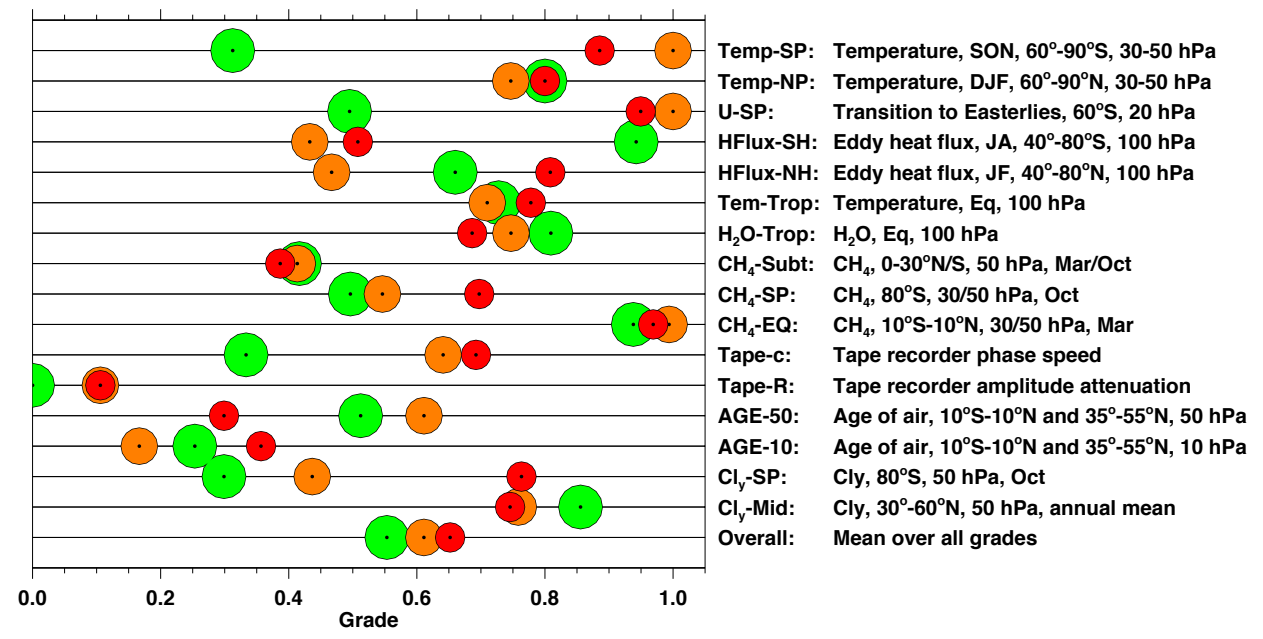

Fig. 13. Grading marks for CCM SOCOLvs2 (green) and SOCOLvs3 with horizontal truncation T31 (orange) and T42 (red). Symbols have different size for better readability. The graded quantities are the same as in Table 2 of Waugh and Eyring (2008).

"The tape recorder indicates very rapid ascent in the tropical lower stratosphere. The tape recorder attenuation and $\mathrm{CH}_{4}$ gradients both indicate too much mixing and/or too much vertical diffusion in SOCOLvs2".

The analysis of the tape recorder signal in SOCOLvs 3 reveals a slowdown of the vertical ascent in the tropics (by about $10 \%)$, but the upwards propagation is still too fast. While the attenuation of the tape recorder signal indicates a reduced horizontal mixing in SOCOLvs3, the opposite is the case for the horizontal $\mathrm{CH}_{4}$ gradients (Fig. $6 \mathrm{~d}$ and e).

"Model values of $\mathrm{Cl}_{\mathrm{y}}$ and $\mathrm{Br}_{\mathrm{y}}$ in the upper stratosphere exceed the values expected from the prescribed halocarbon scenarios. Vortex $\mathrm{Cl}_{\mathrm{y}}$ is well below the observations. This indicates a lack of mass conservation in SOCOLvs2".

The simulated upper-stratospheric values of $\mathrm{Cl}_{\mathrm{y}}$ and $\mathrm{Br}_{\mathrm{y}}$ in SOCOLvs3 follow the prescribed halogen scenario and do not show any artificial excess. Furthermore, the overestimated mass loss of $\mathrm{Cl}_{\mathrm{y}}$ in the polar vortex is no longer evident in SOCOLvs3. Overall, the advanced, massconservative advection scheme by Lin and Rood (1996) led to a significantly improved representation of $\mathrm{Cl}_{\mathrm{y}}$ and $\mathrm{Br}_{\mathrm{y}}$, which reflects a more realistic simulation of ozone in SOCOLvs3.

"SOCOLvs2 performs well to very well for the annual mean and the annual cycle in ozone, in near global column ozone, and in the variability of column ozone in the Northern polar cap. The model fails to represent the annual cycle in southern polar column ozone and variability".

SOCOLvs3 shows a clearly improved annual cycle in total column ozone, which was not realistically captured by
SOCOLvs2, especially in tropical and mid-latitudes. As a consequence of the increased vortex $\mathrm{Cl}_{\mathrm{y}}$, SOCOLvs 3 underestimates Antarctic spring total column ozone, which is a degradation compared to SOCOLvs2. However, it should be noted that the apparently good performance of SOCOLvs 2 in this respect was based on error compensation.

The development of the third generation of the SOCOL $\mathrm{CCM}$ and the new insights taken from the model evaluation are a further important step in chemistry-climate modeling and our understanding of complex cause-and-effect relationships concerning model shortcomings. As in SOCOLvs1 (Schraner et al., 2008), several model deficiencies in SOCOLvs2 were related to unfavorable numerical characteristics of the tracer advection scheme and were resolved by applying the advanced transport algorithm of Lin and Rood (1996) in SOCOLvs3. These improvements, together with the high computational efficiency, make SOCOLvs3 a useful modeling tool for studying chemistry-climate interactions.

Acknowledgements. We kindly acknowledge the CCM Validation Activity CCMVal of WCRP/SPARC for providing observational datasets and the CCMVal diagnostic tool, which were partly used for the analysis of the model results. We thank Greg Bodeker (Bodeker Scientific) for providing the combined total column ozone dataset plotted in Fig. 11. We thank Fiona Tummon for her helpful comments on this manuscript. ECMWF ERA-40 and ERA-Interim data used in this study have been obtained from the ECMWF data server. This study was supported by the ETH "Competence Center for Environmental Sustainability" (CCES) through the project MAIOLICA and by the Swiss National Science Foundation (SNF) through the FuMEs project (grant 200021_138037/1). E. Rozanov is partially supported by the SNF under grant CRSI122-130642 (FUPSOL).

Edited by: A. Sandu 


\section{References}

Bodeker, G. E., Shiona, H., and Eskes, H.: Indicators of Antarctic ozone depletion, Atmos. Chem. Phys., 5, 2603-2615, doi:10.5194/acp-5-2603-2005, 2005.

Butchart, N., Charlton-Perez, A. J., Cionni, I., Hardiman, S. C., Haynes, P. H., Krüger, K., Kushner, P. J., Newman, P. A., Osprey, S. M., Perlwitz, J., Sigmond, M., Wang, L., Akiyoshi, H., Austin, J., Bekki, S., Baumgaertner, A., Braesicke, P., Brühl, C., Chipperfield, M., Dameris, M., Dhomse, S., Eyring, V., Garcia, R., Garny, H., Jöckel, P., Lamarque, J.-F., Marchand, M., Michou, M., Morgenstern, O., Nakamura, T., Pawson, S., Plummer, D., Pyle, J., Rozanov, E., Scinocca, J., Shepherd, T. G., Shibata, K., Smale, D., Teyssédre, H., Tian, W., Waugh, D., and Yamashita, Y.: Multimodel climate and variability of the stratosphere, J. Geophys. Res., 116, D05102, doi:10.1029/2010JD014995, 2011.

Cagnazzo, C., Manzini, E., Giorgetta, M. A., Forster, P. M. De F., and Morcrette, J. J.: Impact of an improved shortwave radiation scheme in the MAECHAM5 General Circulation Model, Atmos. Chem. Phys., 7, 2503-2515, doi:10.5194/acp-7-2503-2007, 2007.

Carslaw, K. S., Luo, B. P., and Peter, T.: An analytic-expression for the composition of aqueous $\mathrm{HNO}_{3}-\mathrm{H}_{2} \mathrm{SO}_{4}$ stratospheric aerosols including gas-phase removal of $\mathrm{HNO}_{3}$, Geophys. Res. Lett., 22, 1877-1880, 1995.

Courant, R., Friedrichs, K., and Levy, H.: Über die partiellen Differenzengleichungen der mathematischen Physik, Math. Ann., 100, 32-74, 1928.

Dameris, M., Grewe, V., Ponater, M., Deckert, R., Eyring, V., Mager, F., Matthes, S., Schnadt, C., Stenke, A., Steil, B., Brühl, C., and Giorgetta, M. A.: Long-term changes and variability in a transient simulation with a chemistry-climate model employing realistic forcing, Atmos. Chem. Phys., 5, 2121-2145, doi:10.5194/acp-5-2121-2005, 2005.

Egorova, T., Rozanov, E., Schlesinger, M. E., Andronova, N. G., Malyshev, S. L., Zubov, V., and Karol, I. L.: Assessment of the effect of the Montreal Protocol on atmospheric ozone, Geophys. Res. Lett., 28, 2389-2392, 2001.

Egorova, T., Rozanov, E., Zubov, V., and Karol, I. L.: Model for Investigating Ozone Trends (MEZON), Izvestiya, Atmos. Oceanic Phys., 39, 277-292, 2003.

Egorova, T., Rozanov, E., Manzini, E., Haberreiter, M., Schmutz, W., Zubov, V., and Peter, T.: Chemical and dynamical response to the 11-yr variability of the solar irradiance simulated with a chemistry-climate model, Geophys. 31, L06119, doi:10.1029/2003GL019294, 2004.

Egorova, T., Rozanov, E., Zubov, V., Manzini, E., Schmutz, W., and Peter, T.: Chemistry-climate model SOCOL: a validation of the present-day climatology, Atmos. Chem. Phys., 5, 1557-1576, doi:10.5194/acp-5-1557-2005, 2005.

Eyring, V., Butchart, N., Waugh, D. W., Akiyoshi, H., Austin, J., Bekki, S., Bodeker, G. E., Boville, B. A., Brühl, C., Chipperfield, M. P., Cordero, E., Dameris, M., Deushi, M., Fioletov, V. E., Frith, S. M., Garcia, R. R., Gettelman, A., Giorgetta, M. A., Greve, V., Jourdain, L., Kinnison, D. E., Mancini, E., Manzini, E., Marchand, M., Marsh, D. R., Nagashima, T., Newman, P. A., Nielsen, J. E., Pawson, S., Pitari, G., Plummer, D. A., Rozanov, E., Schraner, M., Shepherd, T. G., Shibata, K., Stolarski, R. S., Struthers, H., Tian, W., and Yoshiki, M.: Assessment of temperature, trace species, and ozone in chemistry-climate model simulations of the recent past, J. Geophys. Res., 111, D22308, doi:10.1029/2006JD007327, 2006.

Eyring, V., Chipperfield, M., Giorgetta, M., Kinnison, D., Manzini, E., Matthes, K., Newman, P., Pawson, S., Shepherd, T., and Waugh, D.: Overview of the New CCMVal Reference and Sensitivity Simulations in Support of Upcoming Ozone and Climate Assessments and the Planned SPARC CCMVal, SPARC Newsletter No. 30, 20-26, available at: http://www.atmosp.physics.utoronto.ca/SPARC/ Newsletter30Web/53294-1\%20SPRAC\%20Newsletter-LR.pdf, 2008.

Fouquart, Y. and Bonnel, B.: Computations of solar heating of the Earth's atmosphere: A new parameterization, Beitr. Phys. Atmos., 53, 35-62, 1980.

Gelman, M. E., Miller, A. J., Johnson, K. W., and Nagatani, R.: Detection of long-term trends in global stratospheric temperature from NMC analyses derived from NOAA satellite data, Adv. Space Res., 6, 17-26, 1996.

Gettelman, A., Birner, T., Eyring, V., Akiyoshi, H., Bekki, S., Brühl, C., Dameris, M., Kinnison, D. E., Lefevre, F., Lott, F., Mancini, E., Pitari, G., Plummer, D. A., Rozanov, E., Shibata, K., Stenke, A., Struthers, H., and Tian, W.: The Tropical Tropopause Layer 1960-2100, Atmos. Chem. Phys., 9, 16211637, doi:10.5194/acp-9-1621-2009, 2009.

Giorgetta, M. A.: Der Einfluss der quasi-zweijährigen Oszillation: Modellrechnungen mit ECHAM4, Max-Planck-Institut für Meteorologie, Hamburg, Examensarbeit Nr. 40, MPI-Report 218, 1996.

Giorgetta, M. A., Manzini, E., Roeckner, E., Esch, M., and Bengtsson, L.: Climatology and forcing of the quasi-biennial oscillation in the MAECHAM5 model, J. Climate, 19, 3882-3901, 2006.

Grewe, V. and Sausen, R.: Comment on "Quantitative performance metrics for stratospheric-resolving chemistry-climate models" by Waugh and Eyring (2008), Atmos. Chem. Phys., 9, 91019110, doi:10.5194/acp-9-9101-2009, 2009.

Grooß, J.-U. and Russell III, J. M.: Technical note: A stratospheric climatology for $\mathrm{O}_{3}, \mathrm{H}_{2} \mathrm{O}, \mathrm{CH}_{4}, \mathrm{NO}_{x}, \mathrm{HCl}$ and $\mathrm{HF}$ derived from HALOE measurements, Atmos. Chem. Phys., 5, 2797-2807, doi:10.5194/acp-5-2797-2005, 2005.

Hall, T. M. and Prather, M. J.: Simulations of the trend and annual cycle in stratospheric $\mathrm{CO}_{2}$, J. Geophys. Res., 98, 10573-10581, doi:10.1029/93JD00325, 1993.

Hanson, D. and Ravishankara, A.: Reactive Uptake of $\mathrm{ClONO}_{2}$ onto Sulfuric Acid Due to Reaction with $\mathrm{HCl}$ and $\mathrm{H}_{2} \mathrm{O}$, J. Phys. Chem., 98, 5728-5735, 1994.

Hanson, D., Ravishankara, A., and Lovejoy, E. R.:, Reaction of $\mathrm{BrONO}_{2}$ with $\mathrm{H}_{2} \mathrm{O}$ on submicron sulfuric acid aerosol and the implications for the lower stratosphere, J. Geophys. Res., 101, 9063-9069, 1996.

Hauglustaine, D. A., Granier, C., Brasseur, G., and Megie G.: The importance of atmospheric chemistry in the calculation of radiative forcing on the climate system, J. Geophys. Res., 99, 11731186, 1994.

Hines, C. O.: Doppler spread parameterization of gravity wave momentum deposition in the middle atmosphere, 1 , Basic formulation, J. Atmos. Solar Terr. Phys., 59, 371-386, 1997 a.

Hines, C. O.: Doppler spread parameterization of gravity wave momentum deposition in the middle atmosphere, 2, Broad and quasi monochromatic spectra and implementation, J. Atmos. So- 
lar Terr. Phys., 59, 387-400, $1997 \mathrm{~b}$.

Horowitz, L. W., Walters, S., Mauzerall, D. L., Emmons, L. K., Rasch, P. J., Granier, C., Tie, X., Lamarque, J.-F., Schultz, M. G., Tyndall, G. S., Orlando, J. J., and Brasseur, G. P.: A global simulation of tropospheric ozone and related tracers: Description and evaluation of MOZART, version 2, J. Geophys. Res., 108, 4784, doi:10.1029/2002JD002853, 2003.

Hoyle, C. R.: Three dimensional chemical transport model study of ozone and related gases 1960-2000, Eidgenössische Technische Hochschule, Zürich, Dissertation No. 16271, available at: http://e-collection.ethbib.ethz.ch/eserv/eth:28651/ eth-28651-01.pdf, 2005.

Intergovernmental Panel on Climate Change (IPCC): The scientific basis, Contribution of working group I to the third assessment report of the Intergovernmental Panel on Climate Change, Cambridge University Press, Cambridge, UK and New York, NY, USA, 2001.

Jöckel, P., von Kuhlmann, R., Lawrence, M. G., Steil, B., Brenninkmeijer, C. A. M., Crutzen, P. J., Rasch, P. J., and Eaton, B.: On a fundamental problem in implementing flux-form advection schemes for tracer transport in 3-dimensional general circulation and chemistry transport models, Q. J. R. Meteorol. Soc., 127, 1035-1052, 2001.

Lean, J., Rottman, G., Harder, J., and Kopp, G.: SORCE contributions to new understanding of global change and solar variability, Sol. Phys., 230, 27-53, 2005.

Lin, S. J. and Rood, R. B.: Multidimensional flux-form semiLagrangian transport schemes, Mon. Weather Rev., 124, 20462068, 1996.

Lohmann, U., Feichter, J., Chuang, C. C., and Penner, J.: Prediction of the number of cloud droplets in the ECHAM GCM, J. Geophys. Res., 104, 9169-9198, 1999.

Manzini, E. and Bengtsson, L.: Stratospheric climate and variability from a general circulation model and observations, Clim. Dynam., 12, 615-639, 1996.

Manzini, E. and Feichter, J.: Simulation of the $\mathrm{SF}_{6}$ tracer with the middle atmosphere MAECHAM4 model: Aspects of the largescale transport, J. Geophys. Res., 104, 31097-31108, 1999.

Manzini, E., Giorgetta, M. A., Esch, M., Kornblueh, L., and Roeckner, E.: The influence of sea surface temperatures on the Northern winter stratosphere: Ensemble simulations with the MAECHAM5 model, J. Climate, 19, 3863-3881, 2006.

Milz, M., Clarmann, T. v., Bernath, P., Boone, C., Buehler, S. A., Chauhan, S., Deuber, B., Feist, D. G., Funke, B., Glatthor, N., Grabowski, U., Griesfeller, A., Haefele, A., Höpfner, M., Kämpfer, N., Kellmann, S., Linden, A., Müller, S., Nakajima, H., Oelhaf, H., Remsberg, E., Rohs, S., Russell III, J. M., Schiller, C., Stiller, G. P., Sugita, T., Tanaka, T., Vömel, H., Walker, K., Wetzel, G., Yokota, T., Yushkov, V., and Zhang, G.: Validation of water vapour profiles (version 13) retrieved by the IMK/IAA scientific retrieval processor based on full resolution spectra measured by MIPAS on board Envisat, Atmos. Meas. Tech., 2, 379-399, doi:10.5194/amt-2-379-2009, 2009.

Mlawer, E., Taubman, S., Brown, P., Iacono, M., and Clough, S.: Radiative transfer for inhomogeneous atmospheres: RRTM, a validated correlated-k model for the longwave, J. Geophys. Res., 102, 16663-16682, 1997.
Monge-Sanz, B. M., Chipperfield, M. P., Simmons, A. J., and Uppala, S. M.: Mean age of air and transport in a CTM: Comparison of different ECMWF analyses, Geophys. Res. Lett., 34, L04801, doi:10.1029/2006GL028515, 2007.

Mote, P., Rosenlof, K., Mclntyre, M., Carr, E., Gille, J., Holton, J., Kinnersley, J., Pumphrey, H., Russell III, J., and Waters, J.: An atmospheric tape recorder: The imprint of tropical tropopause temperatures on stratospheric water vapor, J. Geophys. Res., 101, 3989-4006, 1996.

Newman, P., Nash, E., and Rosenfield, D.: What controls the temperature of the Arctic stratosphere during spring?, J. Geophys. Res., 106, 19999-20010, 2001.

Ozolin, Y.: Modelling of diurnal variations of gas species in the atmosphere and diurnal averaging in photochemical models, Izv. Akad. Nauk. Phys. Atmos. Ocean., 28, 135-143, 1992.

Pawson, S., Kodera, K., Hamilton, K., Shepherd, T. G., Beagley, S. R., Boville, B., Farrara, J. D., Fairlie, T. D. A, Kitoh, A., Lahoz, W. A., Langematz, U., Manzini, E., Rind, D. H., Scaife, A. A., Shibata, K., Simon, P., Swinbank, R., Takacs, L., Wilson, R., AlSaadi, J. A., Amodei, M., Chiba, M., Coy, L., de Grandpre, J., Eckman, R. S., Fiorino, M., Grose, W. L., Koide, H., Koshyk, J. N., Li, D., Lerner, J., Mahlman, J. D., McFarlane, N. A., Mechoso, C. R., Molod, A., O’Neill, A., Pierce, R. B., Randel, W. J., Rood, R. B., and Wu, F.: The GCM-reality inter-comparison project of SPARC (GRIPS): scientific issues and initial results, B. Am. Meteorol. Soc., 81, 781-796, 2000.

Prather, M. J.: Numerical Advection by Conservation of SecondOrder Moments, J. Geophys. Res., 91, 6671-6681, 1986.

Pruppacher, H. and Klett, J.: Microphysics of clouds and precipitation, Springer, Dordrecht, The Netherlands, 2nd Edn., 1997.

Randel, W., Udelhofen, P., Fleming, E., Geller, M., Gelman, M., Hamilton, K., Karoly, D., Ortland, D., Pawson, S., Swonbank, R., Wu, F., Baldwin, M., Chanin, M.-L., Keckhut, P., Labitzke, K., Remsberg, E., Simmons, A., and Wu, D.: The SPARC Intercomparison of Middle-Atmosphere Climatologies, J. Climate, 17, 986-1003, 2004.

Rasch, P. J. and Lawrence, M. G.: Recent developments in transport methods at NCAR. Proceedings of the MPI Workshop on Conservative Transport Methods, B. Machenhauer, Ed., Max Planck Institute for Meteorology Rep. 265, Hamburg, Germany, 65-75, 1998.

Rasch, P. J., Coleman, D. B., Mahowald, N., Williamson, D. L., Lin, S.-J., Boville, B. A., and Hess, P.: Characteristics of Atmospheric Transport Using Three Numerical Formulations for Atmospheric Dynamics in a Single GCM Framework, J. Climate, 19, 22432266, 2006.

Rayner, N. A., Parker, D. E., Horton, E. B., Folland, C. K., Alexander, L. V., and Rowell, D. R.: Global analyses of sea surface temperature, sea ice, and night marine air temperature since the late nineteenth century, J. Geophys. Res., 108, 4407, doi:10.1029/2002JD002670, 2003.

Ritchie, H.: Application of a semi-Lagrangian integration scheme to the moisture equation in a regional forecast model, Mon. Weather Rev., 113, 424-435, 1985.

Roche, A. E., Kumer, J. B., Mergenthaler, J. L., Ely, G. A., Uplinger, W. G., Potter, J. F., James, T. C., and Sterritt, L. W.: The Cryogenic Limb Array Etalon Spectrometer (CLAES) on UARS: Experiment Description and Performance, J. Geophys. Res., 98, 10763-10775, 1993. 
Roche, A. E., Kumer, J. B., Mergenthaler, J. L., Nightingale, R. W., Uplinger, W. G., Ely, G. A., Potter, J. F., Wuebbles, D. J., Connell, P. S., and Kinnison, D. E.: Observations of Lower Stratospheric $\mathrm{ClONO}_{2}, \mathrm{HNO}_{3}$, and Aerosol by the UARS CLAES Experiment, between January 1992 and April 1993, J. Atmos. Sci., 51, 2877, doi:10.1175/15200469(1994)051<2877:OOLSCH>2.0.CO;2, 1994.

Roeckner, E., Arpe, K., Bengtsson, L., Christoph, M., Claussen, M., Dümenil, L., Esch, M., Giorgetta, M., Schlese, U., and Schulzweida, U.: The atmospheric general circulation model ECHAM-4: Model description and simulation of present dayclimate, Max-Planck-Institut für Meteorologie, Hamburg, Report No. 218, 1996.

Roeckner, E., Bäuml, G., Bonaventura, L., Brokopf, R., Esch, M., Giorgetta, M., Hagemann, S., Kirchner, I., Kornblueh, L., Manzini, E., Rhodin, A., Schlese, U., Schulzweida, U., and Tompkins, A.: The atmospheric general circulation model ECHAM 5. PART I: Model description, Max-PlanckInstitut für Meteorologie, Hamburg, Report No. 349, available at: http://www.mpimet.mpg.de/fileadmin/publikationen/Reports/ max_scirep_349.pdf, last access: 2 September 2013, 2003.

Roeckner, E., Brokopf, R., Esch, M., Giorgetta, M., Hagemann, S., Kornblueh, L., Manzini, E., Schlese, U., and Schulzweida, U.: Sensitivity of simulated climate to horizontal and vertical resolution in the ECHAM5 atmosphere model, J. Climate, 19, 37713791, 2006.

Rozanov, E., Schlesinger, M. E., Zubov, V., Yang, F., and Andronova, N. G.: The UIUC three-dimensional stratospheric chemical transport model: Description and evaluation of the simulated source gases and ozone, J. Geophys. Res., 104, 1175511781, 1999.

Rozanov, E., Schlesinger, M. E., and Zubov, V.: The University of Illinois, Urbana-Champaign three-dimensional stratospheretroposphere general circulation model with interactive ozone photochemistry: Fifteen-year control run climatology, J. Geophys. Res., 106, 27233-27254, 2001.

Sander, S. P., Friedl, R. R., Golden, D. M., Kurylo, M. J., Moortgat, G. K., Keller-Rudek, H., Wine, P. H., Ravishankara, A. R., Kolb, C. E., Molina, M. J., Finlayson-Pitts, B. J., Huie, R. E., and Orkin, V. L.: Chemical kinetics and photochemical data for use in atmospheric studies, Evaluation Number 15, JPL Publication 06-2, Jet Propulsion Laboratory, Pasadena, 2006.

Schraner, M., Rozanov, E., Schnadt Poberaj, C., Kenzelmann, P., Fischer, A. M., Zubov, V., Luo, B. P., Hoyle, C. R., Egorova, T., Fueglistaler, S., Brönnimann, S., Schmutz, W., and Peter, T.: Technical Note: Chemistry-climate model SOCOL: version 2.0 with improved transport and chemistry/microphysics schemes, Atmos. Chem. Phys., 8, 5957-5974, doi:10.5194/acp-8-59572008, 2008.

Schultz, M. and Rast, S. (Eds.): Emission data sets and methodologies for estimating emissions (http://retro.enes.org/reports/D1-6_ final.pdf), REanalysis of the TROpospheric chemical composition over the past 40 years, A long-term global modelling study of tropospheric chemistry funded under the 5th EU framework programme, EUContract No. EVK2-CT-2002-00170, 2007.

Simmons, A. J., Burridge, D. M., Jarraud, M., Girard, C., and Wergen, W.: The ECMWF medium-range prediction model: Development of the numerical formulations and the impact of increased resolution, Meteorol. Atmos. Phys., 40, 28-60, 1989.
Simmons, A., Uppala, S., Dee, D., and Kobayashi, S.: ERA-Interim: New ECMWF reanalysis products from 1989 onwards, ECMWF Newsletter, No. 110, Winter 2006.

SPARC: SPARC Report on the Evaluation of Chemistry-Climate Models, edited by: Eyring, V., Shepherd, T. G., and Waugh, D. W., SPARC Report No. 5, WCRP-132, WMO/TD-No. 1526, http://www.atmosp.physics.utoronto.ca/SPARC, 2010.

Stenke, A., Grewe, V., and Ponater, M.: Lagrangian transport of water vapour and cloud water in the ECHAM4 GCM and its impact on the cold bias, Clim. Dynam., 31, 491-506, doi:10.1007/s00382-007-0347-5, 2008.

Stenke, A., Dameris, M., Grewe, V., and Garny, H.: Implications of Lagrangian transport for simulations with a coupled chemistry-climate model, Atmos. Chem. Phys., 9, 5489-5504, doi:10.5194/acp-9-5489-2009, 2009.

Stott, P. A. and Harwood, R. S.: An implicit time-stepping scheme for chemical species in a global atmospheric circulation model, Ann. Geophys., 11, 377-388, 1993, http://www.ann-geophys.net/11/377/1993/.

Struthers, H., Bodeker, G. E., Austin, J., Bekki, S., Cionni, I., Dameris, M., Giorgetta, M. A., Grewe, V., Lefèvre, F., Lott, F., Manzini, E., Peter, T., Rozanov, E., and Schraner, M.: The simulation of the Antarctic ozone hole by chemistry-climate models, Atmos. Chem. Phys., 9, 6363-6376, doi:10.5194/acp-9-63632009, 2009.

Swinbank, R. and O' Neill, A.: A stratosphere-troposphere data assimilation system, Mon. Weather Rev., 122, 686-702, 1994.

Thomason, L. and Peter, T.: Assessment of Stratospheric Aerosol Properties (ASAP), SPARC Report No. 4., WCRP-124, WMO/TD-No. 1295, 2006.

Turman, B. N. and Edgar, B. C.: Global lightning distributions at dawn and dusk, J. Geophys. Res., 87, 1191-1206, 1982.

Uppala, S. M., Kållberg, P. W., Simmons, A. J., Andrae, U., Da Costa Bechtold, V., Fiorino, M., Gibson, J. K., Haseler, J., Hernandez, A., Kelly, G. A., Li, X., Onogi, K., Saarinen, S., Sokka, N., Allan, R. P., Andersson, E., Arpe, K., Balmaseda, M. A., Beljaars, A. C. M., Van De Berg, L., Bidlot, J., Bormann, N., Caires, S., Chevallier, F., Dethof, A., Dragosavac, M., Fisher, M., Fuentes, M., Hagemann, S., Hólm, E., Hoskins, B. J., Isaksen, L., Janssen, P. A. E. M., Jenne, R., Mcnally, A. P., Mahfouf, J.F., Morcrette, J.-J., Rayner, N. A., Saunders, R. W., Simon, P., Sterl, A., Trenberth, K. E., Untch, A., Vasiljevic, D., Viterbo, P., and Woollen, J.: The ERA-40 reanalysis, Q. J. R. Meteorol. Soc., 131, 2961-3012, 2005.

Waugh, D. W. and Eyring, V.: Quantitative performance metrics for stratospheric-resolving chemistry-climate models, Atmos. Chem. Phys., 8, 5699-5713, doi:10.5194/acp-8-5699-2008, 2008.

Williamson, D. L. and Rasch, P. J.: Two-dimensional semiLagrangian transport with shape-preserving interpolation, Mon. Weather Rev., 117, 102-129, 1989.

WMO: Scientific assessment of ozone depletion: 2006, Global ozone research and monitoring project-report No. 50, World Meteo., Geneva, Switzerland, 2007.

Zubov, V., Rozanov, E., and Schlesinger, M. E.: Hybrid scheme for three-dimensional advective transport, Mon. Weather Rev., 127, 1335-1346, 1999. 